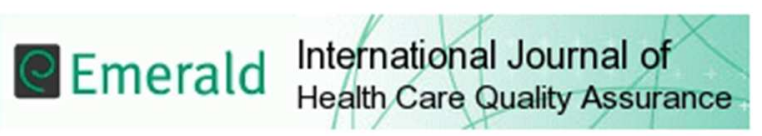

The Impact of Lean bundles on Hospital Performance, Does Size Matter?

\begin{tabular}{|c|c|}
\hline Journal: & International Journal of Health Care Quality Assurance \\
\hline Manuscript ID & IJHCQA-07-2015-0083.R3 \\
\hline Manuscript Type: & Original Article \\
\hline Keywords: & Lean Bundles, Healthcare, Hospital Performance, Jordan \\
\hline
\end{tabular}




\title{
The Impact of Lean bundles on Hospital Performance, Does Size Matter?
}

\begin{abstract}
Structured Abstract:
Purpose: The purpose of this research is to study the effect of the implementation of lean bundles on hospital performance in private hospitals in Jordan and evaluate how much the size of organization can affect the relationship between lean bundles implementation and hospital performance.
\end{abstract}

Design/Methodology/Approach: The research is considered as quantitative method (descriptive and hypothesis testing). Three statistical techniques were adopted to analyse the data. Structural Equation Modelling (SEM) techniques and multi-group analysis were used to examine the research's hypothesis, and to perform the required statistical analysis of the data from the survey. Reliability analysis and confirmatory factor analysis were used to test the construct validity, reliability, and measurement loadings that were performed.

Findings: Lean bundles have been identified as an effective approach that can dramatically improve the organizational performance of private hospitals in Jordan. Main lean bundles- Just In Time, Human Resource Management, and Total Quality Management are applicable to large, small and medium hospitals without significant differences in advantages that depend on size.

Original/Value: According to the researchers' best knowledge, this is the first research that studies the impact of lean bundles implementation in healthcare sector in Jordan. This research also makes a significant contribution for decision makers in health care to increase their awareness of lean bundles.

Keywords: Lean Bundles, Healthcare, Jordan, Hospital Performance.

Article Classification: Research paper

Received $-8^{\text {th }}$ July 2015

Revised $-10^{\text {th }}$ August 2015

Revised $-28^{\text {th }}$ February 2016

Accepted -

\section{Introduction}

The process of healthcare work improvement receives attention due to its importance as a vital sector in economy (Ghosh and Sobek, 2015). With its connection with human life, healthcare has one of the most significant roles in society and requires important investments and constant development (Cheng et al., 2015). Healthcare, is a vital sector in the Jordanian economy since independence because of its considerable contributions to employment and revenue generation (Al-Saa'da et al., 2013). The establishment of many modern medical colleges in Jordan shows its seriousness in providing quality healthcare to its citizens, as well as to its visitors and tourists (Halasa and Nandakumar, 2009; Med Tourism Co, LLC, 2014).

Hospitals are often characterized as particularly complex systems interacting with a wide variety of heterogeneous actors, and requiring close coordination of activities across interdependent units to provide a customer service (Shazali et al., 2013; Ghosh and Sobek, 
2015). Given the recognition of a complex environment, focus has been directed on the need for organizations to match that complexity to remain viable by applying one of the most valuable production system and service offering which is the Japanese Lean Production System (LPS).

Over the last decade, lean has been applied to the health service industry where it has been associated with increasing quality, efficiency through improved clinical processes, and it shortens the time between order placement and product delivery by eliminating inefficiencies and waste in workflow processes (Drotz and Poksinska, 2014; Sara et al., 2015; Cheng et al., 2015). Also, it gives healthcare professionals a chance to redesign their work in a more effective way without requiring extra resources leading to patient satisfaction with care (Leggat et al., 2015; Nayar et al., 2016; Jorma et al., 2016). According to Silva et al., (2015) lean office health techniques can provide benefits to healthcare in developing countries' hospitals.

Reviewing the literature about lean implication in healthcare points to a shortage of extensive research on this subject in the developing countries (Laura and Priti, 2011; Ghosh and Sobek, 2015). The overwhelming majority of studies have been conducted in industrial fields (Albliwi et al., 2015). This observation provides scope for the following questions:

Is there any effect of the three main bundles of lean (Just In Time, Total Quality Management, and Human Resource Management) implementation on organizational hospital performance? Is there any effect of the size of the hospitals on the relationship between lean bundles implementation and hospital performance?

\section{Background}

Lean concept was introduced firstly by Krafjick in 1988 in his article "Triumph of the Lean Production System" which focused on the idea of using less of everything to increase the efficiency and productivity in organizations (Laura and Priti, 2011). Marodin et al., (2013), used "Lean Production" as a term to describe the power of Toyota production system which requires less human resources, space, capital, material, inventory and time to make a greater and wide variety of products with fewer defects. In any situation where wastes are supposed to appear and efficiency is needed to be increased, lean is a great scope to make things better, faster and cheaper. Because of that, lean concept is considered universal since it is applies to many fields (Wong et al., 2014).

The development of lean concept originally started in the automotive industry, delivering high quality product and services while improving organizational performance and satisfying customers (Shazali et al., 2013; Nayar et al., 2016). Then the concept migrated into many sectors beyond automotive, including service and healthcare (Poksinska et al., 2013; Ghosh and Sobek, 2015).

\section{Lean bundles}

The authors systematically reviewed the literature. According to Albliwi et al., (2015), one of the advantages of undertaking the systematic review approach is becoming aware of the breadth of research and the theoretical background in a specific field.

The literature identifies lean philosophy as a bundle of associated practices installed as a system (Wickramasinghe and Wickramasinghe, 2011). Lean manufacturing has become an integrated system that includes highly inter-related elements and wide management practices (Furlan et al., 2011). Researchers maintain that it is the implementation of the whole set of lean practices that leads companies to higher performance, due to the relationships between practices (Dal Pont et al., 2008). 
Lean bundles create an efficient operation, and pull together best practices and concepts. This includes just in time, total quality management, human resource management, continuous improvement, resource planning and supply chain management (Jadhav et al., 2014). According to Dal Pont et al., (2008), Lean philosophy translates into a collection of practices and techniques i.e. lean manufacturing bundles that both implement and support the lean approach.

Shah and Ward (2003) define lean manufacturing as a multi-dimensional approach that encompasses a wide variety of management bundles, including just-in-time (JIT), total quality management (TQM), total preventive maintenance (TPM), and human resource management (HRM) in an integrated system to investigate their effects on operational performance. The main function of lean production is that the previous bundles can work synergistically to develop a high quality system that leads to produce a finished product at the pace of customer demand with little or no waste.

After reviewing the literature about the bundles that affect lean implementation, the researchers have selected three bundles from Table I to test the complementarity effects on performance of three of the main lean manufacturing bundles, namely Just in Time (JIT), Total Quality Management (TQM) and Human Resource Management (HRM). Researchers maintain that it is the implementation of the whole set of lean bundles that leads businesses to high performance, due to the synergistic effects among practices (Shah and Ward 2003; Furlan et al., 2011). Dal Pont et al., (2008) propose that the synergistic effects of bundling practices will finally lead to an overall performance that is greater than the sum of the performance contributions of each of its parts.

\section{Table 1 here}

\section{Just in Time (JIT)}

JIT is a method which states that an organization should produce the right item with specific required value at the right time, helping to satisfy the customer and reducing inventories, space utilization and possible wastes (Burgess and Radnor, 2013; Belekoukias et al., 2014). Moreover, Furlan et al., (2011) and Shah and Ward, (2007) defined JIT as a bundle which includes practices that aims at reducing or eliminating waste along the value streams such as lot size reduction, and cycle time reduction.

The competitive benefits of JIT management are well implemented in both manufacturing and service industries, since service and manufacturing firms both employ processes to create an end product or service. According to Jarrett, (2006), the inventory reduction and improved customer service would be the major benefits achieved from implementation of JIT systems in the service industries. Some researchers such as De Souza (2009, p.133) defined Just-in-Time as "one of the tools used in lean practice that aims to reduce buffers between steps. In healthcare, it can be seen as reducing internal queues of patients to smooth a process".

\section{Total Quality Management (TQM)}

TQM is a firm-wide management philosophy that continuously improves, sustains and controls the quality of products, services and processes by focusing on the customers' needs and expectations to enhance customer satisfaction and firm performance (Esin and Hial, 2014; Dal Pont et al., 2008). Within lean settings, TQM has been enriched by lean practices geared at reducing manufacturing process variance, which in turn leads to continuous improvement (Shah 
and Ward, 2007; Dal Pont et al., 2008; Furlan et al., 2011). These practices include standard operation procedure and problem solving teamwork, statistical process control, visual display, cleanness and order (Doolen and Hacker, 2005; Rocha-lona et al., 2013).

Kannan and Tan, (2005) demonstrated that JIT, TQM and supply chain management practices are mutually supportive, and that their synergy contributes positively to firms' performance. The manufacturing units implementing both JIT and TQM practices have increased quality, as well as producing what customers want, when they want, with a reasonable price when compared to manufacturing units implementing only JIT practices (Furlan et al., 2011). Dal Pont et al., (2008) suggest that TQM practices lead to decreased internal and external product reject rates and production downtime. In healthcare, the challenge to lean adoption is that the quality manager's role within the hospital must change from one of recognizing and tracking unfavourable events, to one of reducing the risk of unfavourable events and support doctors and nurses with the redesign of processes to improve quality (Mannon, 2014).

\section{Human Resource Management (HRM)}

The target of HRM, as a lean principle, is the reduction of quality defects with the use of tools that include mistake proofing devices, visual control systems and a full working system (Belekoukias et al., 2014; Burgess and Radnor, 2013). HRM practices such as participation, training and performance monitoring, are considered to be performance enhancing in hospitals, as they influence employee attitudes and behaviours which ultimately impact on individual and organizational performance (Leggat et al., 2015). Cua et al., (2001) also showed how lean programs include some HR practices. Their analysis made clear how the implementation of these human practices, together with TQM, JIT, and TPM programs, provides significant explanation for the differences in performance measures.

The literature on high-performance HRM practices also identifies HR factors adapted to an LP environment, including team work, job rotation, continuous training, job security, multiskilling and engagement (Martínez-Jurado et al., 2013; Hadid and Mansouri, 2014). On the other hand, dealing effectively with LP requires motivated, skilled workers and the integration of HR practices into a firm's production strategy (Bonavia and Marin-Garcia, 2011). Lorden et al., (2014) identified three human factors essential to successful lean implementation in health care sector: communication, leadership, and workload. According to Nicholas (2012), all lean methods center on a team of workers mostly from the process that is to be improved. In healthcare the team would include clinicians and staff from the targeted process and others from related processes (e.g., purchasing, housekeeping, maintenance). Their participation is important not only for implementing improvements, but also for sustaining the improvements.

HRM relies on employees' commitment and involvement and this is achieved through a streamlined organizational structure with decentralized authority, multi-functional training programs and collaboration/communication between the whole workforces (Shah and Ward, 2007; Alsmadi et al., 2012). Leaders using timely two-way communication through organizational hierarchy and across departments find successful implementations of their initiatives (Lorden et al., 2014).

These are the three principles originally generated in manufacturing fields, but they can also be adopted and applied in services fields. JIT is associated with basic control techniques. TQM is a set of basic techniques to reduce process variance. HRM is a set of practices that shape the organizational environment in which the basic techniques are implemented (Shamah, 2013; Furlan et al., 2011). 
Lean Healthcare Implementation and Performance

Recent studies have explored the relationship between lean healthcare bundling practices and healthcare performance. Many studies had proven that implementation lean in healthcare lead positive results for healthcare performance. According to Shazali et al., (2013), two healthcare organizations in the US showed positive effect on productivity, cost, quality and timely delivery of services after applying lean through organization. Lean system increases the customer satisfaction, financial savings and levels of knowledge management; and a reduction in inventories and process wastes (AL-Najem et al., 2013). According to Jorma et al., (2016), the most important targets in healthcare lean implementations are cost reductions and increment of productivity simultaneously.

From 2003 to 2015 , the selected measurements of performance to investigate the effects of lean bundles vary considerably between researches. Hon (2005) measured lean performance by calculating time, cost, quality, flexibility and productivity simultaneously. In 2007, Shah and Ward measured performance in terms of cost, quality, lead time, processing time and operations time. Alsmadi et al., (2012), Shazali et al., (2013) and Butler and Leong (2000) measured performance by different variables: customer satisfaction, employee satisfaction, cycle time, production cost, rate of assets (ROA), market share, overall productivity and labor productivity. Karim and Arif-Uzaman (2013) said that cost-related measures and competitor- related measures are most significant for lean performance evaluation and measurements.

The researchers selected Shazali et al., (2013) and Butler and Leong (2000) classifications of performance measurements and translated these dimensions to questions in the questionnaire to measure the hospital performance as a dependent variable in research model.

\section{Size of organization}

Previous studies refer to the classification of hospitals by type, by geographical areas, by function, by funding, by accreditation and by number of beds (Loux et al., 2005). Most of the classifications used measure the performance of hospitals and hospital size based on the number of beds. Hospital bed capacity is the number of beds which a hospital has been designed and constructed to contain. It may also refer to the number of beds set up and staffed for use.

Bhasin (2012) found that large organizations that implemented lean manufacturing achieved higher improvements in their performance compared to small and medium sized enterprises (SMEs). Hadid (2014) and Karim and Arif-Uz-zaman (2013) found that the firm size has an impact on the adaptation of lean practices because large firms are argued to have more financial and human resources allowing more experimentation with new technologies and innovations (e.g. lean practices) that may improve their productivity and efficiency.

Broadly, Large Enterprises (LEs) and Small and Medium sized Enterprises (SMEs) are the two main groups of organisations. Therefore, Lean sacrifices the economies of scale of mass production and aims instead to provide superior customer value through holistic process optimisation, both within the firm and up and down the supply chain (Hu et al., 2015). Lean has been increasingly recognised as a key development concept for all types of firms to improve their operations. In the literature, it is obvious that SMEs can employ a range of approaches and lean tools to facilitate lean implementation (Hu et al., 2015).

In Jordan, the only classification for hospitals is based on two main factors; the ownership of a hospital (governmental or private sector) and the purpose of the hospital itself in terms of being an educational or non-educational hospital. This current classification in Jordan does not help the research in assessing the impact of lean implementation on hospital 
performance according to the size of organization. Therefore, our research classifies hospitals based on size (number of beds) as considered by Loux et al.,(2005), in which hospitals were classified into three size categories: SMEs (small (fewer than 50 beds), medium (50-99 beds), and large (100 or more beds).

\section{Research Framework}

In the light of the gap identified in the previous section, the current study proposes a conceptual model which explores the link between applying lean bundles on organization performance in Jordanian private hospitals.

Our discussion and measurement of lean bundles is necessarily related to the practices that are commonly observed in the literature describing high performance since the practices are complementary to each other. Therefore, the researchers hypothesize that simultaneous application of multiple aspects of lean bundles will have a significant positive impact on performance (Shah and Ward, 2003; Carlborg et al., 2013).

We use seven items for JIT, four items for TQM, nine items for HRM, and eight items for hospital performance. Finally, the relationship between dependent and independent variables can be modified by the size of organization (as moderate variable) depending on Rahman et al., (2010), Karim and Arif-Uz-zaman (2013). This study's research model evaluates how the following groups of variables affect the hospital performance (See Figure 1).

\section{Figure 1 here}

Therefore, based on critical review of the existing literature and the developed conceptual framework, the following hypotheses of the study have been developed:

H1: The JIT bundle has a positive and direct effect on hospital performance.

H2: The TQM bundle has a positive and direct effect on hospital performance.

H3: The HRM bundle has a positive and direct effect on hospital performance.

H4: Hospital size moderates the impact of lean bundles on hospital performance.

\section{Research Methodology}

Based on the census of economic establishments for the year 2013 issued by the Department of Statistics, there are 58 private hospitals in the various governorates of the Kingdom, and 37 of them are located in the capital, Amman. This research considered the 58 private hospitals in Jordan as the population of the research. The sample framework is the 37 private hospitals in Amman.

According to the researchers' observation, these hospitals usually receive the large number of customers based on statistical distribution of hospitals and beds by governorates and health sectors for 2013 (DOS, 2013). The private hospitals in the capital Amman contain 2966 beds out of 3989 distributed in hospitals in the private sector in the Kingdom.

According to the Department of Statistics' reports for 2013, the Ministry of Health has 16464 employees compared with private health sector which employs 39263 people. Therefore, the private hospitals in the Kingdom in general and specifically in the capital Amman have a critical role in Jordanian economy, and their management is interested in using the up-to-date systems in managing both staff and operations.

In order to achieve the research objectives, the survey has been distributed to the managers (leading positions) in some departments who obtain the knowledge about the lean 
practices in their hospitals and have a great understanding about the level of organizational performance. The related departments are: operational department, marketing department, quality assurance department, HRM department, and supply chain department. 5 participants representing each hospital have been selected. The researcher chose the purposive sampling technique to select the research sample. According to the data, a total of 105 questionnaires were returned from 185 questionnaires distributed to 37 hospitals, 105 of which were useable. This translates into a response rate of $56.8 \%$.

The 20 items concerning lean bundles are measured on a 1-5 Likert scale ranging from strongly disagree (1) to strongly agree (5) asking informants for their perception of the actual implementation of each practice. The eight items concerning performance are measured on a 1-5 Likert scale ranging from "much worse" to "much better" in this study.

\section{Profile of firm}

\section{Table II here}

Table II indicates that $57 \%$ of the sample is classified as big hospital (more than 100 beds) and this requires more staff to make the daily work professionally. This manifests that $62 \%$ have more than 200 employees. It is also found that $44.8 \%$ of the sample have been established for more than 20 years, this is due to the fact that health sector is one of the oldest service sectors in Jordan.

\section{Validity and reliability}

Convergent and discriminate validity were both assessed using a confirmatory factor analysis (CFA) model testing approach. The fit indices are the $\chi 2 / \mathrm{df}=1.629$, standardized root mean square residual $(\mathrm{SRMR})=0.056$, comparative fit index $(\mathrm{CFI})=.906$, and the incremental fit index $($ IFI $)=90.8$. According to the threshold values suggested by $\mathrm{Hu}$ and Bentler (1999), our model can be accepted. The discriminate validity was supported because the average variance extracted (AVE) is greater than 0.50 and square root of AVE is greater than each correlation coefficient as shown in table (3). Convergent validity of the measured variables were verified through confirmatory factor analysis and correlation analysis, because (1) all item loadings should be significant and exceed 0.7 ; (2) composite reliabilities (CR) should be more than 0.8 ; and (3) average variance extracted (AVE) for each construct should exceed 0.50 were well above the recommended value shown in table (4). Thus, convergent validity was supported. Cronbach's alpha is used to assess the reliability of scales, existing scales should have alpha values higher than .70 (Hair et al., 1995), all constructs Cronbach's alpha were ranged from .710 to .908 which confirm the scale reliability.

An important aspect of construct validity is the validation of second-order constructs as depicted in Figure 2. According to Marsh and Hocevar, (1985), second order validity exists if target coefficient $(\mathrm{T})$ is calculated as the ratio of the chi-square of the first-order model to the chi-square of the second order model between $0.80-1.00$. The results of analysis indicted the target coefficient is equal $.94(438.201 / 463.789)$ which confirm existence of a second-order construct.

\section{$\underline{\text { Table III here }}$}

$\underline{\text { Table IV here }}$ 


\section{Figure 2 here}

Finally, because self-reported, single-respondent data, common method variance (CMV) might be a threat to the validity of our results. CMV arises because of respondents' need to provide consistent answers and/or answers that are socially desirable. We conducted Harman's single factor (one-factor) test for the possibility of CMV in the single-respondent data of the sample (Podsakoff et al., 2003). Confirmatory factor analysis (CFA) was performed to compare $\chi^{2}$ difference between a single-factor model where all the measurement items were loaded onto a single factor and a model where the measurement items were loaded onto the study factors. The chi-square test demonstrated that the four-factor model was superior to the single-factor model $\left(\Delta \chi^{2}=321.953 ; \Delta \mathrm{df}=8 ; P<0.01\right)$. Consequently, according to this method, no CMV problem should be expected.

\section{Analysis of lean bundles implementation JIT (Just in Time)}

Table IV intended to investigate just in time practices in surveyed hospitals. The results show high degree of implementing Just In Time bundles. The private hospitals in Jordan have a good knowledge about how to deal with suppliers and there is an effective supplier participation in operational system. Lack of sufficient experience in how to deal with the optimum setups got the lowest results because the hospitals are located within the service sector, not industrial.

\section{HRM (Human Resources Management)}

Hospitals realize that greater employee involvement has the central role in determining both the competitive advantage of the firm and the quality of services. Hospital structure is relatively flat (Horizontal structure) shows the lowest results, since the administration system used in sample organizations is centralized, due to the dominant use of vertical organizational chart. The use of such system is due to the application of traditional methods in administration that rely on administrative hierarchy.

\section{TQM (total quality management)}

The quality issues have been discussed in health care for a number of years, and quality programs are required for accreditation by HCAC. Hospital adopting direct contact methods with customers got the highest results, because they are aware that in Jordan's highly competitive market, if these hospitals want to survive, they should maintain an accepted level of customer satisfaction and loyalty.

\section{Hospital performance}

Every hospital in the sample has a vigorous inclination toward customer satisfaction. This result also indicates that administrators are pursuing customer satisfaction more than any other performance dimensions. So, better outcomes for patients generally imply more accessible care with shortened treatment time and waiting time (Shazali et al., 2013). Current Ratio (Current Assets/Current Liabilities) got the lowest results, because few respondents of the questionnaire have information about financial profile of their firms. Therefore, most of the answers of these questions depend on the respondents ' own estimations and expectations. 
Testing the research hypotheses

Structural Equation modeling (SEM) was needed to test the proposed hypotheses and multivariate relationships. The results of SEM for the hypothesized model on Table (5) and figure (3) show that the path from lean bundles to hospital performance. The model fit indices are $\chi 2 / \mathrm{df}=(1.690), \mathrm{CFI}=.902, \mathrm{RMSEA}=0.078$, and $\mathrm{SRMR}=0.0663, \mathrm{TLI}=.904$, these indices are acceptable (Hu and Bentler, 1999).

\section{Figure 3 here}

\section{Table V here}

The results of the analysis showed that there is a positive significant impact of JIT on hospital performance supporting Hypothesis $1(\beta=0.295, \mathrm{P}<0.05)$. The benefits gained from just in time implementation included lower non-value added activities, lower inventory level, higher quality, higher flexibility, and better response time and all these benefits improved organizational performance of hospitals in terms of cost reduction, productivity, inventory minimization and quality. Therefore, H1 was accepted.

HRM and TQM are found to significantly influence hospital performance. Thus, the proposed positive effect $(\mathrm{H} 2)$ and $(\mathrm{H} 3)$ are supported where $(\beta=0.314, \mathrm{P}<0.05)$ and $(\beta=-.217, \mathrm{P}$ $<0.05)$ accordingly.

In addition, each of the dimensions of lean bundles; JIT, TQM, and HRM explained a variance of $51 \%$ in hospital performance. From previous results, the research emphasize that lean bundles should not be implemented individually and no practice can stand alone and be expected to achieve better performance than all practices combined. The findings in this section agree with the previous researches done in the field (Furlan et al., 2011; Shah and Ward 2007).

To test (H4), a multi-group analysis was used via Amos. This procedure satisfies the recommended guidelines of having at least a couple of cases per free parameter in each model for each large and SMEs (Marsh et al., 1998). This research first compared a fully constrained model in which the paths are constrained equally across subgroups to an unconstrained model. The results on Table 6 showed that there is no significant differences in the impact of lean bundles on hospital performance between large and small and medium hospital $(\Delta \chi=23.5$, $\mathrm{p}>0.05$ ). Thus $\mathrm{H} 4$ is not supported.

\section{Table VI here}

\section{Discussion, conclusion and implications}

The findings of this study contribute to the existing literature of knowledge by studying the effect of the implementation of lean bundles on hospital performance. The results of data analysis revealed that the implementation of lean bundles in Jordanian private hospitals has a positive effect on overall healthcare performance and has a positive impact on quality, cost, patient and staff satisfaction.

The result of our study indicates that TQM implementation helps hospitals to identify and eliminate areas generating the most waste and to improve department workflows, thereby increasing overall service quality. Therefore, the results of our study are consistent with the findings of previous research studies such as Rocha-lona et al. (2013) and Abdelhadi (2015) who found that TQM leads to improve performance by improving and sustaining the quality of service 
Many previous research studies such as Taj and Morosan (2011) and Shah and Ward (2007) stressed the role of employees, as they are the key to problem-solving team, lead process/service improvement efforts and maintain excellent records of all activities regularly which leads to improve all over productivity, which is one of the most important criteria of performance. The research findings indicated that HRM, as one of the lean bundles, brings benefits to hospitals as performance improvement. Thus, our findings are in line with previous research done in the field which illustrated a strong relationship between human resource management and hospital performance. For instance, Bonavia and Marin-Garcia, (2011), found that some of the HRM practices have a significant impact on employee turnover, and productivity.

Our findings pointed out that JIT minimizes wastes generated in the process, ensuring greater productivity, reducing the required time from patients and processed materials, and forcing hospitals to deal with suppliers, service providers, and customers all over the world. Thus, the findings of the present research confirm some previous findings presented in the existing literature (Belekoukias et al., 2014; Nawanir et al., 2013; Dora et al., 2013).

We expected and hypothesised that hospital size moderates the impact of lean bundles on hospital performance. The results of data analysis were in some way surprising and our hypothesis was not supported. However, other authors have found different results.

Many researchers have assumed that size does not affect a firm's ability to implement lean system, and that SMEs can implement such systems just as effectively as large business (Shah and Ward, 2003; AL-Najem et al., 2013; Raghunath and Jayathirthav, 2014; HU et al., 2015). In reality, large companies and SMEs are able to gain the benefits of lean system (Raghunath and Jayathirthav, 2014). According to HU et al., (2015), lean can be suitable to all sizes of enterprise in their activities to become more competitive to sustain, and possibly enhance, their position in the modern marketplace. Rymaszewska (2014) emphasize the successful adoption of lean among SMEs. The author highlights the capability of lean to address the challenges that companies, regardless of their size, face.

Strong leadership culture and committed management support the cornerstone for success in implementing any idea regardless of organisation size (Achanga et al., 2006).

SMEs have a better chance of adapting to change compared with large firms, as they are less hierarchical and less bureaucratic than large firms, and can therefore adopt and form the information across entire departments more efficiently than large one (HU et al., (2015). According to Belekoukias et al. (2014), the waste minimization affects more SMEs compared to large organisations. SMEs are privately owned, with the owner taking a long-term perspective and commitment to developing and sustaining their business. Shah and Ward (2003) found that it is not always advantageous that large size will lead to higher operational performance and that in many cases; large size has a negative impact on the operational performance when the effects of JIT, TQM, TPM and HRM are taken into consideration. Large organizations suffer from structural inertial forces that negatively affect the implementation of lean manufacturing practices.

According to Shazali et al., (2013) lean initiative does not focus on large scale investments, but it gives healthcare organizations an alternative methodology for achieving improvement without high investments. In addition, these results are inconsistent with the results of previous studies, including Bhasin (2012) and Rahman et al., (2010). The main reason for the difference in results is the study environment. Most of the previous studies that used the size of organization as a moderate variable of the relationship between lean bundles and performance 
done in industrial environment and manufacturers as a targeted sample. While the study environment in this research is the service environment and healthcare sector which is a targeted sample. The organizational performance of those hospitals can be driven substantially by lean system implementation without significant differences of the advantages that depend on size.

The results of this study offer several managerial 'take-away' implications for practitioners and policy makers in order to enhance the implementation of lean bundles, as an effective approach that can dramatically improve the organizational performance of hospitals. Firstly, the tools of lean bundles should be used effectively to reduce the time, effort and resources required for improvement in the health care sector. Therefore, public policy makers in Jordan should increase their awareness of lean bundles, concepts and benefits for improving service quality and optimizing hospital performance in Jordan.

Secondly, hospitals should have an effective leadership at the top and at the middle management levels to eliminate all obstacles towards the achievement of lean bundles goals. Moreover, the top management in healthcare sector must educate and empower staff which leads to the involvement of all the employees in the process.

\section{Limitations and implications for future studies}

Although the study objectives were accomplished, several limitations of the study should be noted.

Firstly, this study was limited to private hospitals of a certain health sector within a specific small country context. Therefore, caution must be exercised in extending and generalizing our findings to large public hospitals and other contexts. However, our study could be considered as a foundation for future studies in other countries and sectors. In particular, it is recommended to replicate our study in many other service industries such as hotel industry, consultancy services and telecommunications industry.

Secondly, not all the groups of variables of lean system implementation that affect the hospital performance were examined, and there might be other factors influencing the hospital performance.

Finally, it is recommended to develop more cross-sector comparisons between the service and manufacturing sectors, and assess the readiness of SMEs to embark on a lean journey 


\section{References}

Abdelhadi, Abdelhakim. (2015), 'Investigating Emergency Room Service Quality Using Lean Manufacturing', International Journal of Health Care Quality Assurance, Vol. 28 No. 5, pp. 510-519.

Achanga, P., Shehab, E., Roy, R., and Nelder, G. (2006), 'Critical Success Factors for Lean Implementation within SMEs', Journal of Manufacturing Technology Management, Vol. 17 No. 4, pp. 460-471.

Albliwi, A., Antony, .J, and Lim, H. (2015), 'A Systematic Review of Lean Six Sigma for the Manufacturing Industry’, Business Process Management Journal, Vol. 21 No. 3.

AL-Najem, M., Dhakal, H., Labib, A., and Bennett, N. (2013), 'Lean Readiness Level within Kuwaiti Manufacturing Industries", International Journal of Lean Six Sigma, Vol. 4 No. 3, pp. $280-320$.

Al-Saa'da, J., Taleb, A., Abdallat, A., Elian, M., Al-Mahasneh, A., Nimer, A., and Al-Weshah, A. (2013), 'Supply Chain Management and Its Effect on Health Care Service Quality: Quantitative Evidence from Jordanian Private Hospitals', Journal of Management \& Strategy, Vol. 4 No. 2, pp. 42-51.

Alsmadi, M., Almani, A., and Jerisat, R. (2012), 'A Comparative Analysis of Lean Practices and Performance in the UK Manufacturing and Service Sector Firms', Total Quality Management \& Business Excellence, Vol. 23 No. 3-4, pp. 381-396.

Behrouzi, F., and Wong, K. Y. (2011), 'Lean Performance Evaluation of Manufacturing Systems: a Dynamic and Innovative Approach', Procedia Computer Science, Vol. 3, pp. 388-395.

Belekoukias, I., Garza-Reyes, J. A., and Kumar, V. (2014), 'The Impact of Lean Methods and Tools on the Operational Performance of Manufacturing Organizations', International Journal of Production Research, Vol. 52 No. 18, pp. 5346-5366.

Bhasin, S. (2012), 'Performance of Lean in large Organisations', Journal of Manufacturing Systems, Vol. 31 No. 3, pp. 349-357.

Bonavia, T., and Marin-Garcia, J. (2011), 'Integrating Human Resource Management into Lean Production and their Impact on Organizational Performance', International Journal of Manpower, Vol. 32 No. 8, pp. 923- 938.

Burgess, N., and Radnor, Z. (2013), 'Evaluating Lean in healthcare', International Journal of Health Care Quality Assurance, Vol. 26 No. 3, pp. 220-235.

Butler, W., and Leong, K. (2000), 'The Impact of Operations Competitive Priorities on Hospital Performance', Health Care Management Science, Vol. 3 No. 3, pp. 227-235.

Carlborg, P., Kindström, D., and Kowalkowski, C. (2013), 'A Lean Approach for Service Productivity Improvements: Synergy or Oxymoron', Managing Service Quality: An International Journal, Vol. 23 No. 4, pp. 291-304.

Cheng, S., Bamford, D., Papalexi, M., and Dehe, B. (2015), 'Improving Access to Health Services-Challenges in Lean Application', International Journal of Public Sector Management, Vol. 23 No. 22, pp. 121-135.

Cua, K., McKone, K., and Schroeder, G. (2001), 'Relationships' between Implementation of TQM, JIT, and TPM and Manufacturing Performance', Journal of Operations Management, Vol. 19 No.6, pp.675-694.

Dal Pont, G., Furlan, A., and Vinelli, A. (2008), 'Interrelationships among Lean Bundles and their effects on Operational Performance', Oper Manag Res, Vol. 1 No. 2, pp. 150-158. 
De Souza, B. (2009), 'Trends and Approaches in Lean Healthcare', Leadership in Health Services, Vol. 22 No. 2, pp. 121-139

Doolen, L., and Hacker, E. (2005), 'A Review of Lean Assessment in Organizations: an Exploratory Study of Lean Practices by Electronics Manufacturers', Journal of Manufacturing Systems, Vol. 24 No. 1, pp. 55-67.

Department of Statistics, Jordan (2013), 'Jordan in Figures', Amman: Department of Statistic (In Arabic).

Dora, M., Van Goubergen, D., Kumar, M., Molnar, A., and Gellynck, X. (2013), 'Application of Lean Practices in Small and Medium-Sized Food Enterprises', British Food Journal, Vol. 116 No. 1, pp. 125-141.

Drotz, E., and Poksinska, B. (2014), 'Lean in Healthcare from Employees' Perspectives', Journal of Health Organization and Management, Vol. 28 No. 2, pp. 177 - 195.

Esin, S., and Hial, O. (2014), 'The Effects of Total Quality Management Practices on Performance and the Reasons of and the Barriers to TQM Practices in Turkey', Advances in Decision Sciences, Vol. 2014, pp. 1-17.

Farzad, B., and Kuan, W. (2011), 'An Investigation and Identification of Lean Supply Chain Performance Measures in the automotive SMEs', Scientific Research and Essays, Vol. 6 No. 24, pp. 5239-5252.

Furlan, A., Vinelli, A., and Dal Pont, G. (2011), 'Complementarity and Lean Manufacturing Bundles: an Empirical Analysis', International Journal of Operations \& Production Management, Vol. 31 No. 8, pp. 835-850.

Ghosh, M., and Sobek D. (2015), 'A Problem-Solving Routine for Improving Hospital Operations' Journal of Health Organization and Management, Vol. 29 No. 2, pp. 252-270.

Hadid, W. (2014), 'The Relationship between Lean Service, Activity-Based Costing and business strategy and their Impact on Performance', Brunel University Brunel Business School, $\mathrm{PhD}$ Theses.

Hadid, Wael and Mansouri, Afshin. (2014), 'The Lean-Performance Relationship in Services: a Theoretical Model'. International Journal of Operations \& Production Management, Vol. 34 No. 6, pp. 750-785.

Hair, F., Anderson, E., Tatham, L., and Black, C. (1995), Multivariate Data Analysis, 4th ed. Prentice Hall, Upper Saddle River, NJ.

Halasa, Y., and Nandakumar, K. (2009), 'Factors Determining Choice of Health Care Provider in Jordan', Eastern Mediterranean Health Journal, Vol. 15 No. 4, pp.959-968.

Hon, B. (2005), 'Performance and Evaluation of Manufacturing Systems', CIRP AnnalsManufacturing Technology, Vol. 54 No. 2, pp. 139-154.

Hu, L., and Bentler, M. (1999), 'Cutoff Criteria for Fit Indexes in Covariance Structure Analysis: Conventional Criteria Versus New Alternatives', Structural Equation Modelling, Vol. 6 No. 1, pp. 1-55.

Hu, Q., Mason, R., Williams, S., and Found, P. (2015), 'Lean Implementation within SMEs: a Literature Review', Journal of Manufacturing Technology Management, Vol. 26 No. 7.

Jadhav, J., Mantha, S., and Rane, S. (2014), 'Exploring Barriers in Lean Implementation', International Journal of Lean Six Sigma, Vol. 5 No. 2, pp. 122-148.

Jagdish, J., Mantha, S., and Santosh, R. (2014), 'Development of Framework for Sustainable Lean Implementation: an ISM Approach', Journal of Industrial Engineering International, Vol. 10 No. 27, pp. 4-27. 
Jarrett, P. (2006), 'An Analysis of International Health Care Logistics: The Benefits and Implications of Implementing Just-in-Time Systems in the Health Care Industry', Leadership in Health Services, Vol. 19 No. 1, pp. 1-10.

Jorma, T., Tiirinki, H., Bloigu, R., and Turkki, L. (2016), 'Lean Thinking in Finnish Healthcare', Leadership in Health Services, Vol. 29 No. 1, pp. 9 - 36.

Karim, A., and Arif-Uz-zaman, K. (2013), 'A Methodology for Effective Implementation of Lean Strategies and its Performance Evaluation in Manufacturing Organizations', Business Process Management Journal, Vol. 19 No. 1, pp. 169-196.

Kannan, V., Tan, K. (2005), 'Just in Time, Total Quality Management, and Supply Chain Management: Understanding their Linkages and impact on Business Performance', Omega, Vol. 33, pp. 153-162.

Loux, L., Payne, S., and Knott, A. (2005), Comparing Patient Safety in Rural Hospitals by Bed Count, Agency for Healthcare Research and Quality, Rockville Md.

Lorden, A., Zhang, Y., Lin, S., and Cote, M. (2014), 'Measures of Success: The Role of Human Factors in Lean Implementation in Healthcare', Quality Management Journal, Vol. 21 No. 3, pp. 26-37.

Lura, R., and Priti, Sh. (2011), 'Lean Service Implementation in Hospital: A Case Study Conducted in University Clinical Centre of Kosovo, Rheumatology Department', Master Thesis, Umea School of Business, Sweden.

Leggat, S., Bartram, T., Stanton, P., Bamber, G., and Sohal A. (2015), 'Have Process Redesign Methods, such as Lean, been Successful in Changing Care Delivery in Hospitals? A Systematic Review', Public Money \& Management, Vol. 35 No.2, pp. 161-168.

Marodin, A., and Saurin, A. (2013), 'Implementing Lean Production Systems: Research Areas and Opportunities for Future Studies', International Journal of Production Research, Vol. 51 No. 22, pp. 6663-6680.

Marsh, W., Hau, T., Balla, R., and Grayson, D. (1998), 'Is more ever too much? The Number of Indicators per Factor in Confirmatory Factor Analysis', Multivariate Behavioural Research, Vol. 33 No. 2, pp. 181-220.

Marsh, H., and Hocevar, D. (1985), 'Application of Confirmatory Factor Analysis to the Study of Self-concept: First- and Higher-order Factor Models and their Invariance Across Groups', Psychological Bulletin, Vol. 97 No. 3, pp. 145-52.

Mannon, M. (2014), 'Lean Healthcare and Quality Management: The Experience of ThedaCare', Quality Management Journal, Vol. 21 No. 1, pp. 7-10.

Martínez-Jurado, P., Moyano-Fuentes, J., and Gómez, P. (2013), 'HR Management during Lean Production Adoption', Management Decision, Vol. 51 No. 4, pp. 742 - 760.

Med Tourism Co, LLC http://www.medicaltourismco.com/jordan-hospitals/medical-tourismjordan.php (last accessed April 2014).

Nawanir, G., Teong, Lim., and Othman S. (2013), 'Impact of Lean Practices on Operations Performance and Business Performance', Journal of Manufacturing Technology Management, Vol. 24 No. 7, pp. 1019-1050.

Nayar, P., Ojha, D., Fetrick, A., and Nguyen, A. (2016), 'Applying Lean Six Sigma to improve Medication Management', International Journal of Health Care Quality Assurance, Vol. 29 No. 1, pp. 16 - 23.

Nicholas, John. (2012), 'An Integrated Lean-Methods Approach to Hospital Facilities Redesign', Hospital Topics, Vol. 90 No.2, pp. 47-55. 
Podsakoff, P., MacKenzie, S., Lee, J., and Podsakoff, P. (2003), 'Common Method Biases in Behavioural Research: a Critical Review of the Literature and Recommended Remedies', Journal of Applied Psychology, Vol. 88 No. 5, pp. 879-903.

Poksinska, B., Swartling, D., and Drotz, Total. (2013), 'The Daily Work of Lean Leaders Lessons from Manufacturing and Healthcare', Erik Quality Management, Vol. 24 No. 8, pp. 886-898.

Rahman, S., Laosirihongthong, T., and Sohal, S. (2010), 'Impact of Lean Strategy on Operational Performance: a Study of Thai Manufacturing Companies', Journal of Manufacturing Technology Management, Vol. 21 No. 7, pp. 839-852.

Raghunath, A., Jayathirtha, R.V. (2014), 'Six Sigma Implementation by Indian Manufacturing SMEs - an Empirical Study', Academy of Strategic Management Journal, Vol. 13 No. 1, pp. 35-55.

Rocha-Lona, L., Garza-Reyes, A., and Kumar, V. (2013), Building Quality Management Systems: Selecting the Right Methods and Tools, CRC Press.

Rymaszewska, Anna. (2014), 'The Challenges of Lean Manufacturing Implementation in SMEs', Benchmarking: An International Journal, Vol. 21 No. 6, pp. 987-1002.

Sara, T., Monica E., Carol T., Mats B., and Johan H. (2015), 'Agile, a Guiding Principle for Health Care Improvement?', International Journal of Health Care Quality Assurance, Vol. 28 No. 5, pp. 486-493.

Shah, R. and Ward, P.T. (2003), 'Lean Manufacturing: Context, Practice Bundles, and Performance', Journal of Operations Management, Vol. 21 No. 2, pp. 129-149.

Shah, R., and Ward, T. (2007), 'Defining and Developing Measures of Lean Production', Journal of Operations Management, Vol. 25 No. 4, pp. 785-805.

Shamah, A. (2013), 'Measuring and Building Lean Thinking for Value Creation in Supply Chains', International Journal of Lean Six Sigma, Vol. 4 No. 1, pp. 17-35.

Shazali, A., Habidin, F., Ali, N., Khaidir, A., and Jamaludin, H. (2013), 'Lean Healthcare Practice and Healthcare Performance in Malaysian Healthcare Industry', International Journal of Scientific and Research Publications, Vol. 3 No. 1, pp. 1-5.

Silva, I., Seraphim, E., Agostinho, O., Junior, O., and Batalha, G. (2015), 'Lean Office in Health Organization in the Brazilian Army', International Journal of Lean Six Sigma, Vol. 6 No. 1, pp. 2 - 16.

Taj, S., and Morosan, C. (2011), 'The impact of Lean Operations on the Chinese Manufacturing Performance', Journal of manufacturing technology management, Vol. 22, No. 2, pp. 223240.

Tan, W. (2011), 'Managing Lean Projects: Understanding the Structures of Lean Production', International Journal of Construction Management, Vol. 11 No. 3, pp. 67-78.

Wong, W., Ignatius, J., and Soh, K. (2014), 'What is the Leanness Level of your Organization in Lean Transformation Implementation? An Integrated Lean Index Using ANP Approach', Production Planning \& Control: The Management of Operations, Vol. 25 No. 4, pp. 273-287.

Wickramasinghe, D., and Wickramasinghe, V. (2011), 'Perceived Organisational Support, Job Involvement and Turnover Intention in Lean Production in Sri Lanka', International Journal of Advanced Manufacturing Technology, Vol. 55 No. 5-8, pp. 817-830.

Zhou, B. (2012), 'Lean Principles, Practices, and Impacts: a Study on small and Medium-Sized Enterprises (SMEs)’, Annals of Operations Research, No. 1, pp. 1-18. 
Table I: Reviewing the body of knowledge for lean bundling practices

\begin{tabular}{|c|c|c|c|c|c|c|c|c|c|c|c|}
\hline Research & $V S$ & $C I$ & $J I T$ & $T Q M$ & Perfection & $H R M$ & $\begin{array}{l}\text { Zero } \\
\text { defects }\end{array}$ & $M F T$ & $V I S$ & $T P M$ & COST \\
\hline Albliwi et al., 2015 & & & • & $\bullet$ & & • & & & & & $\bullet$ \\
\hline Hu et al., 2015 & & & $\bullet$ & $\bullet$ & & $\bullet$ & & & & & $\bullet$ \\
\hline Jagdish et al., 2014 & 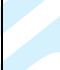 & & $\bullet$ & $\bullet$ & & $\bullet$ & & & & & \\
\hline Belekoukias et al. ,2014 & 8 & $\bullet$ & $\bullet$ & & & - & & & & - & \\
\hline Tan, W, 2011 & $\bullet$ & C & • & & & $\bullet$ & & & & & \\
\hline Shazali et al., 2013 & & $\bullet$ & & & & $\bullet$ & & & & & \\
\hline $\begin{array}{l}\text { Burgess and Radour, } \\
2013\end{array}$ & • & $\bullet$ & $\bullet$ & 80 & $\bullet$ & & & & & & \\
\hline Alsmadi et al. ,2012 & & $\bullet$ & $\bullet$ & • & & • & & & & & \\
\hline Zhou, B, 2012 & & & $\bullet$ & $\bullet$ & 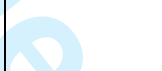 & & & & & & \\
\hline Dal Pont et al., 2008 & & & $\bullet$ & $\bullet$ & & $\bullet$ & & & & & \\
\hline Behrozi \& Wong, 2011 & & $\bullet$ & $\bullet$ & & & 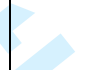 & $\bullet$ & $\bullet$ & $\bullet$ & & \\
\hline Furlan et al., 2011 & & $\bullet$ & $\bullet$ & $\bullet$ & & $\bullet$ & & & & & \\
\hline Farzad \& kuan, 2011 & & $\bullet$ & $\bullet$ & $\bullet$ & & $\bullet$ & & & & & $\bullet$ \\
\hline Laura \&pariti, 2011 & • & & $\bullet$ & & - & $\bullet$ & 8 & & & & \\
\hline Cua et al., 2001 & & & - & $\bullet$ & $\bullet$ & & & & & $\bullet$ & \\
\hline Shah and Ward, 2003 & & & $\bullet$ & $\bullet$ & & $\bullet$ & & $\nabla$ & & $\bullet$ & \\
\hline
\end{tabular}


Table II: Descriptive statistics of sample's organisation characteristics

\begin{tabular}{|l|l|l|l|l|l|l|l|l|}
\hline Number of employees & Freq & $\%$ & $\begin{array}{l}\text { Age of } \\
\text { hospital }\end{array}$ & Freq & $\%$ & Number of beds & Freq & $\%$ \\
\hline 50 employees or less & 1 & $1 \%$ & $0-3$ & 11 & $10.5 \%$ & Less than 50 & 20 & $19.1 \%$ \\
\hline Between 51and 100 & 13 & $12.4 \%$ & $4-7$ & 0 & $0 \%$ & From 50 to 100 & 25 & $23.8 \%$ \\
\hline Between 101 and 150 & 14 & $13.3 \%$ & $8-11$ & 8 & $7.6 \%$ & More than 100 & 60 & $57.1 \%$ \\
\hline Between 151and 200 & 12 & $11.4 \%$ & $12-15$ & 24 & $22.9 \%$ & Total & 105 & $100 \%$ \\
\hline More than 200 & 65 & $61.9 \%$ & $16-19$ & 15 & $14.3 \%$ & & & \\
\hline Total & 105 & $100 \%$ & +20 & 47 & $44.8 \%$ & & & \\
\hline
\end{tabular}

Table III: Interconstruct Correlations

\begin{tabular}{|l|c|c|c|c|}
\hline constructs & JIT & TQM & HRM & Performance \\
\hline JIT & $(.735)$ & & & \\
\hline TQM & $.395^{* *}$ & $(.774)$ & & \\
\hline HRM & $.630^{* *}$ & $.516^{* *}$ & $(.728)$ & $(.831)$ \\
\hline performance & $.618^{* *}$ & $.642^{* *}$ & $.640^{* *}$ & - \\
\hline $\begin{array}{l}\text { Note: Square root of AVE are shown on the diagonal of each matrix; } \\
\text { Interconstruct correlation is shown off the diagonal }\end{array}$ \\
\hline$* *$ Sig<.01, *Sig<.05
\end{tabular}

Table IV: Measurement of confirmatory factor analysis - convergent validity/ Means and Standard Deviations for sample's responses toward research questions.

\begin{tabular}{|c|c|c|c|c|c|c|c|c|}
\hline$J I T$ & $\begin{array}{l}\text { Factor } \\
\text { loading }\end{array}$ & Mean & stdev & Level & Rank & $C R$ & $A V E$ & $\alpha$ \\
\hline $\begin{array}{l}\text { Hospital usually completes daily schedule as } \\
\text { planned }\end{array}$ & 0.764 & 3.87 & .858 & high & 3 & \multirow{7}{*}{.86} & \multirow{7}{*}{.54} & \multirow{7}{*}{.862} \\
\hline $\begin{array}{l}\text { The layout of institution floor facilitates low } \\
\text { inventories and fast throughput }\end{array}$ & 0.707 & 3.78 & .740 & high & 5 & & & \\
\hline $\begin{array}{l}\text { Suppliers frequently deliver materials to } \\
\text { hospital }\end{array}$ & 0.784 & 4.15 & .703 & high & 1 & & & \\
\hline Customers receive JIT deliveries from hospital & 0.711 & 3.84 & .846 & high & 4 & & & \\
\hline Hospital have low setup times of equipment's & 0.722 & 3.59 & .858 & Medium & 7 & & & \\
\hline Hospital actively develops customer's services & 0.733 & 4.12 & .850 & high & 2 & & & \\
\hline $\begin{array}{l}\text { Hospital uses pull-based production system } \\
\text { (according to customer order) }\end{array}$ & 0.733 & 3.72 & .909 & high & 6 & & & \\
\hline \multicolumn{2}{|l|}{ Overall mean } & 3.86 & & high & & & \multicolumn{2}{|c|}{ 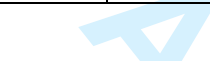 } \\
\hline
\end{tabular}




\section{HRM (human resource management)}

Hospital encourages team work to achieve common goals, rather than encourages individual work

Management tells us why our suggestions either implemented or not

Hospital structure is relatively flat (Horizontal structure)

Employees receive training to perform multiple tasks

Employees receive training and development in workplace skills regularly

Hospital adopts all aspects of continuous improvement

Employees undergo cross-functional training/

Employees tend to involve problem solving teams

Employees lead service/process improvement efforts

Employees are empowered and encouraged to improve the services/ processes within the hospital

Overall mean

\section{TQM (total quality management)}

Hospital adopts direct contact methods with customers

Customers provide feedback on quality and delivery performance

Hospital employs regular customer satisfaction surveys

Hospital frequently in close contact with suppliers Overall mean

\section{Hospital performance}

Overall customer satisfactions

Worker Productivity.

Revenue Growth.

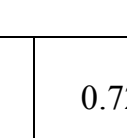

(1)

(2)

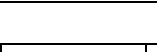

0.648

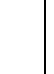

0.694

4.17

0.6

0.688

\begin{tabular}{|l|l|}
\hline 3.51 & 3.78 \\
\hline
\end{tabular}

\begin{tabular}{|l|l|l}
\hline 0.688 & 3.7 \\
\hline & 0.749
\end{tabular}

\begin{tabular}{|c|c|c|}
0.749 & 3.71 & .883 \\
\hline 0.831 & 3.86 & .815 \\
0.807 & 3.73 & .828
\end{tabular}

0.807

(1).

0.724

0.67

0.673

\begin{tabular}{|l|l} 
& 3.77 \\
\hline & 3.75 \\
\hline
\end{tabular}

.837

\begin{tabular}{l|l|l}
\multicolumn{2}{|c|}{} & \\
high & &
\end{tabular} 
Table V: Path analysis for the constructs of the study

\begin{tabular}{|l|l|l|c|c|c|}
\hline \multicolumn{2}{|l|}{ Path } & Estimate & C.R. & $P$ \\
\hline Performance & $<---$ & JIT & .295 & 3.674 & .000 \\
\hline Performance & $<---$ & TQM & .217 & 2.977 & .003 \\
\hline Performance & $<---$ & HRM & .314 & 3.663 & .000 \\
\hline R2 & \multicolumn{3}{|c|}{.513} \\
\hline
\end{tabular}

Table VI: Results of the multigroup analysis

\begin{tabular}{|c|c|c|c|c|c|c|c|c|c|}
\hline \multicolumn{3}{|l|}{ Models } & $\chi^{2}$ & $d f$ & $\Delta \chi^{2}$ & $\Delta d f$ & $\chi^{2}$ difference test & $\begin{array}{l}\text { Small \& } \\
\text { medium } \\
\text { size }\end{array}$ & large size \\
\hline \multicolumn{3}{|c|}{ 1. Baseline Model } & 1023.2 & 504 & & & & & \\
\hline \multicolumn{3}{|c|}{ 2. Constrained Model } & 1046.7 & 531 & 23.5 & 26 & Insignificant $\mathrm{p}<0.05$ & & \\
\hline \multicolumn{3}{|c|}{ Constrained Path } & & 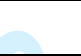 & & & & & \\
\hline Performance & $<--$ & JIT & 1023.2 & 505 & 0 & 1 & Insignificant $\mathrm{p}<0.05$ & .483 & .306 \\
\hline Performance & $<---$ & HRM & 1023.4 & 505 & .2 & 1 & Insignificant $\mathrm{p}<0.05$ & -.167 & .288 \\
\hline
\end{tabular}

Figure 1: Research Model

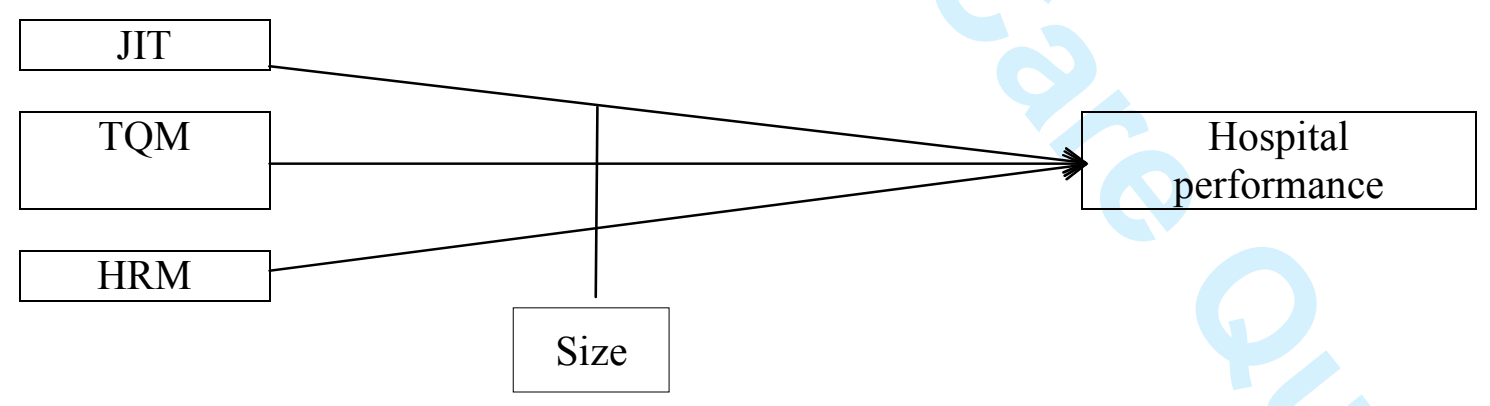


Figure 2: second-order CFA results

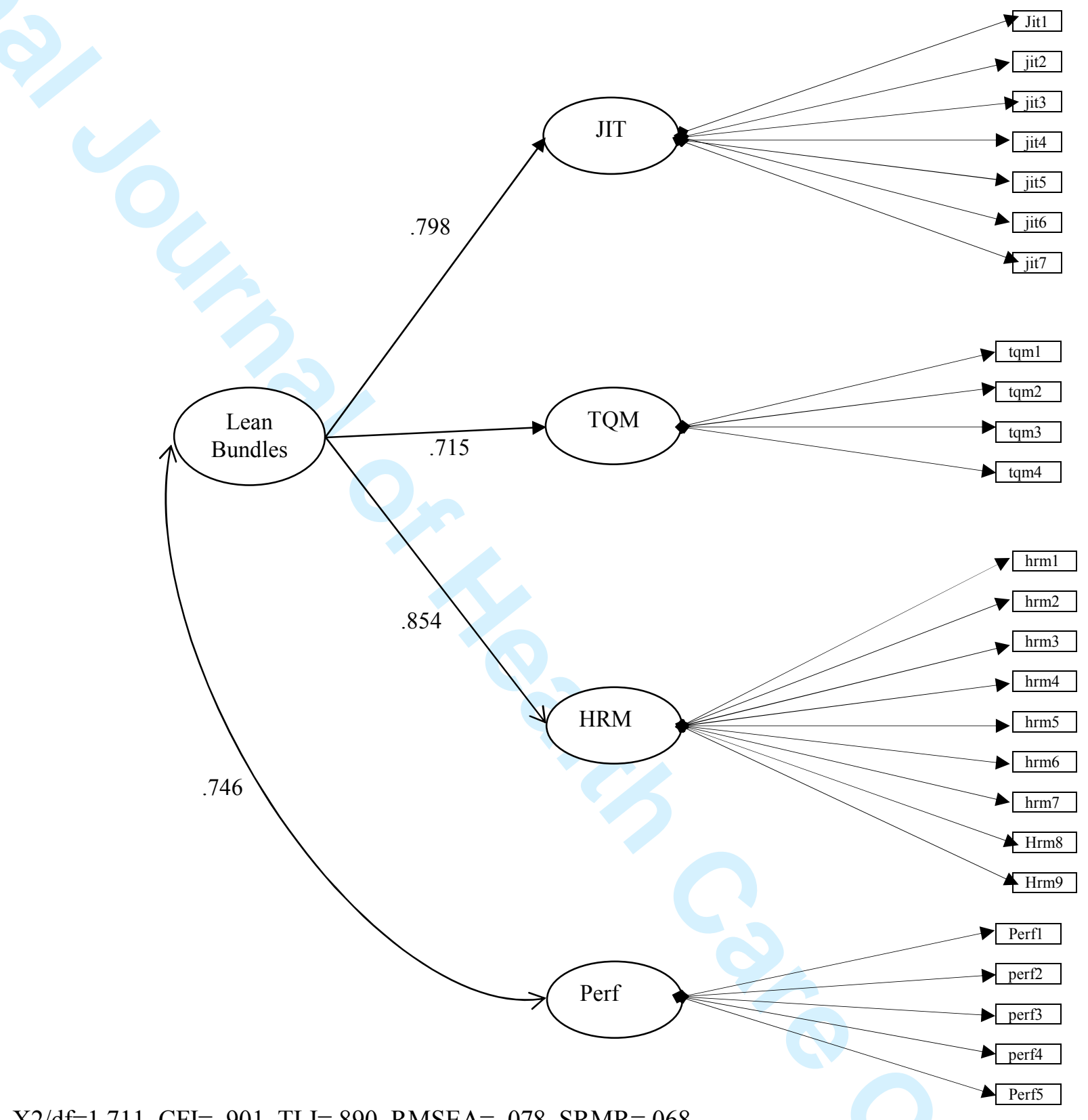

$\mathrm{X} 2 / \mathrm{df}=1.711, \mathrm{CFI}=.901, \mathrm{TLI}=.890, \mathrm{RMSEA}=.078, \mathrm{SRMR}=.068$ 
Figure 3: Structural model with parameter estimates

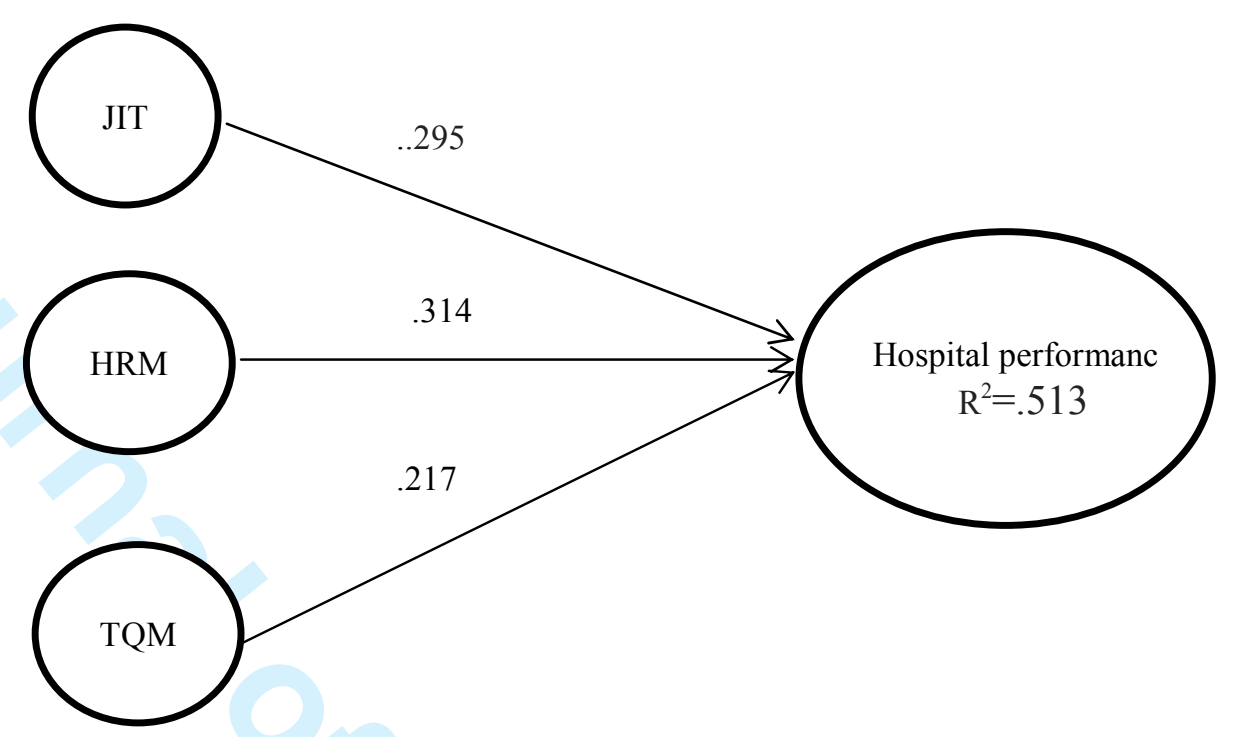




\title{
The Impact of Lean bundles on Hospital Performance, Does Size Matter?
}

\author{
Khalil Al-Hyari, Sewar Abu Hammour \& Mohammad Khair Abu Zaid \\ Faculty of Business, Al-Balqa Applied University, Jordan \\ E-mail: kalhyari@bau.edu.jo \& sewar.abuhammour@hotmail.com \& mohammed_abu_zaid@hotmail.com \\ Mohamed Haffar \\ Faculty of Management, Bournemouth University, UK \\ Email: mhaffar@bournemouth.ac.uk
}

\begin{abstract}
Structured Abstract:
Purpose: The purpose of this research is to study the effect of the implementation of lean bundles on hospital performance in private hospitals in Jordan and evaluate how much the size of organization can affect the relationship between lean bundles implementation and hospital performance.

Design/Methodology/Approach: The research is considered as quantitative method (descriptive and hypothesis testing). Three statistical techniques were adopted to analyse the data. Structural Equation Modelling (SEM) techniques and multi-group analysis were used to examine the research's hypothesis, and to perform the required statistical analysis of the data from the survey. Reliability analysis and confirmatory factor analysis were used to test the construct validity, reliability, and measurement loadings that were performed.

Findings: Lean bundles have been identified as an effective approach that can dramatically improve the organizational performance of private hospitals in Jordan. Main lean bundles- Just In Time, Human Resource Management, and Total Quality Management are applicable to large, small and medium hospitals without significant differences in advantages that depend on size.

Original/Value: According to the researchers' best knowledge, this is the first research that studies the impact of lean bundles implementation in healthcare sector in Jordan. This research also makes a significant contribution for decision makers in health care to increase their awareness of lean bundles.
\end{abstract}

Keywords: Lean Bundles, Healthcare, Jordan, Hospital Performance.

Article Classification: Research paper

Received $-8^{\text {th }}$ July 2015

Revised $-10^{\text {th }}$ August 2015

Revised $-28^{\text {th }}$ February 2016

Accepted - 


\section{Introduction}

The process of healthcare work improvement receives attention due to its importance as a vital sector in economy (Ghosh and Sobek, 2015). With its connection with human life, healthcare has one of the most significant roles in society and requires important investments and constant development (Cheng et al., 2015). Healthcare, is a vital sector in the Jordanian economy since independence because of its considerable contributions to employment and revenue generation (Al-Saa'da et al., 2013). The establishment of many modern medical colleges in Jordan shows its seriousness in providing quality healthcare to its citizens, as well as to its visitors and tourists (Halasa and Nandakumar, 2009; Med Tourism Co, LLC, 2014).

Hospitals are often characterized as particularly complex systems interacting with a wide variety of heterogeneous actors, and requiring close coordination of activities across interdependent units to provide a customer service (Shazali et al., 2013; Ghosh and Sobek, 2015). Given the recognition of a complex environment, focus has been directed on the need for organizations to match that complexity to remain viable by applying one of the most valuable production system and service offering which is the Japanese Lean Production System (LPS).

Over the last decade, lean has been applied to the health service industry where it has been associated with increasing quality, efficiency through improved clinical processes, and it shortens the time between order placement and product delivery by eliminating inefficiencies and waste in workflow processes (Drotz and Poksinska, 2014; Sara et al., 2015; Cheng et al., 2015). Also, it gives healthcare professionals a chance to redesign their work in a more effective way without requiring extra resources leading to patient satisfaction with care (Leggat et al., 2015; Nayar et al., 2016; Jorma et al., 2016). According to Silva et al., (2015) lean office health techniques can provide benefits to healthcare in developing countries' hospitals.

Reviewing the literature about lean implication in healthcare points to a shortage of extensive research on this subject in the developing countries (Laura and Priti, 2011; Ghosh and Sobek, 2015). The overwhelming majority of studies have been conducted in industrial fields (Albliwi et al., 2015). This observation provides scope for the following questions:

Is there any effect of the three main bundles of lean (Just In Time, Total Quality Management, and Human Resource Management) implementation on organizational hospital performance? Is there any effect of the size of the hospitals on the relationship between lean bundles implementation and hospital performance?

\section{Background}

Lean concept was introduced firstly by Krafjick in 1988 in his article "Triumph of the Lean Production System" which focused on the idea of using less of everything to increase the efficiency and productivity in organizations (Laura and Priti, 2011). Marodin et al., (2013), used "Lean Production" as a term to describe the power of Toyota production system which requires less human resources, space, capital, material, inventory and time to make a greater and wide variety of products with fewer defects. In any situation where wastes are supposed to appear and efficiency is needed to be increased, lean is a great scope to make things better, faster and cheaper. Because of that, lean concept is considered universal since it is applies to many fields (Wong et al., 2014).

The development of lean concept originally started in the automotive industry, delivering high quality product and services while improving organizational performance and satisfying customers (Shazali et al., 2013; Nayar et al., 2016). Then the concept migrated into many sectors 
beyond automotive, including service and healthcare (Poksinska et al., 2013; Ghosh and Sobek, 2015).

\section{Lean bundles}

The authors systematically reviewed the literature. According to Albliwi et al., (2015), one of the advantages of undertaking the systematic review approach is becoming aware of the breadth of research and the theoretical background in a specific field.

The literature identifies lean philosophy as a bundle of associated practices installed as a system (Wickramasinghe and Wickramasinghe, 2011). Lean manufacturing has become an integrated system that includes highly inter-related elements and wide management practices (Furlan et al., 2011). Researchers maintain that it is the implementation of the whole set of lean practices that leads companies to higher performance, due to the relationships between practices (Dal Pont et al., 2008).

Lean bundles create an efficient operation, and pull together best practices and concepts. This includes just in time, total quality management, human resource management, continuous improvement, resource planning and supply chain management (Jadhav et al., 2014). According to Dal Pont et al., (2008), Lean philosophy translates into a collection of practices and techniques i.e. lean manufacturing bundles that both implement and support the lean approach.

Shah and Ward (2003) define lean manufacturing as a multi-dimensional approach that encompasses a wide variety of management bundles, including just-in-time (JIT), total quality management (TQM), total preventive maintenance (TPM), and human resource management (HRM) in an integrated system to investigate their effects on operational performance. The main function of lean production is that the previous bundles can work synergistically to develop a high quality system that leads to produce a finished product at the pace of customer demand with little or no waste.

After reviewing the literature about the bundles that affect lean implementation, the researchers have selected three bundles from table I to test the complementarity effects on performance of three of the main lean manufacturing bundles, namely Just in Time (JIT), Total Quality Management (TQM) and Human Resource Management (HRM). Researchers maintain that it is the implementation of the whole set of lean bundles that leads businesses to high performance, due to the synergistic effects among practices (Shah and Ward 2003; Furlan et al., 2011). Dal Pont et al., (2008) propose that the synergistic effects of bundling practices will finally lead to an overall performance that is greater than the sum of the performance contributions of each of its parts.

\section{$\underline{\text { Table I here }}$}

\section{Just in Time (JIT)}

JIT is a method which states that an organization should produce the right item with specific required value at the right time, helping to satisfy the customer and reducing inventories, space utilization and possible wastes (Burgess and Radnor, 2013; Belekoukias et al., 2014). Moreover, Furlan et al., (2011) and Shah and Ward, (2007) defined JIT as a bundle which includes practices that aims at reducing or eliminating waste along the value streams such as lot size reduction, and cycle time reduction.

The competitive benefits of JIT management are well implemented in both manufacturing and service industries, since service and manufacturing firms both employ 
processes to create an end product or service. According to Jarrett, (2006), the inventory reduction and improved customer service would be the major benefits achieved from implementation of JIT systems in the service industries. Some researchers such as De Souza (2009, p.133) defined Just-in-Time as "one of the tools used in lean practice that aims to reduce buffers between steps. In healthcare, it can be seen as reducing internal queues of patients to smooth a process".

\section{Total Quality Management (TQM)}

TQM is a firm-wide management philosophy that continuously improves, sustains and controls the quality of products, services and processes by focusing on the customers' needs and expectations to enhance customer satisfaction and firm performance (Esin and Hial, 2014; Dal Pont et al., 2008). Within lean settings, TQM has been enriched by lean practices geared at reducing manufacturing process variance, which in turn leads to continuous improvement (Shah and Ward, 2007; Dal Pont et al., 2008; Furlan et al., 2011). These practices include standard operation procedure and problem solving teamwork, statistical process control, visual display, cleanness and order (Doolen and Hacker, 2005; Rocha-lona et al., 2013).

Kannan and Tan, (2005) demonstrated that JIT, TQM and supply chain management practices are mutually supportive, and that their synergy contributes positively to firms' performance. The manufacturing units implementing both JIT and TQM practices have increased quality, as well as producing what customers want, when they want, with a reasonable price when compared to manufacturing units implementing only JIT practices (Furlan et al., 2011). Dal Pont et al., (2008) suggest that TQM practices lead to decreased internal and external product reject rates and production downtime. In healthcare, the challenge to lean adoption is that the quality manager's role within the hospital must change from one of recognizing and tracking unfavourable events, to one of reducing the risk of unfavourable events and support doctors and nurses with the redesign of processes to improve quality (Mannon, 2014).

\section{Human Resource Management (HRM)}

The target of HRM, as a lean principle, is the reduction of quality defects with the use of tools that include mistake proofing devices, visual control systems and a full working system (Belekoukias et al., 2014; Burgess and Radnor, 2013). HRM practices such as participation, training and performance monitoring, are considered to be performance enhancing in hospitals, as they influence employee attitudes and behaviours which ultimately impact on individual and organizational performance (Leggat et al., 2015). Cua et al., (2001) also showed how lean programs include some HR practices. Their analysis made clear how the implementation of these human practices, together with TQM, JIT, and TPM programs, provides significant explanation for the differences in performance measures.

The literature on high-performance HRM practices also identifies HR factors adapted to an LP environment, including team work, job rotation, continuous training, job security, multiskilling and engagement (Martínez-Jurado et al., 2013; Hadid and Mansouri, 2014). On the other hand, dealing effectively with LP requires motivated, skilled workers and the integration of HR practices into a firm's production strategy (Bonavia and Marin-Garcia, 2011). Lorden et al., (2014) identified three human factors essential to successful lean implementation in health care sector: communication, leadership, and workload. According to Nicholas (2012), all lean methods center on a team of workers mostly from the process that is to be improved. In healthcare the team would include clinicians and staff from the targeted process and others from 
related processes (e.g., purchasing, housekeeping, maintenance). Their participation is important not only for implementing improvements, but also for sustaining the improvements.

HRM relies on employees' commitment and involvement and this is achieved through a streamlined organizational structure with decentralized authority, multi-functional training programs and collaboration/communication between the whole workforces (Shah and Ward, 2007; Alsmadi et al., 2012). Leaders using timely two-way communication through organizational hierarchy and across departments find successful implementations of their initiatives (Lorden et al., 2014).

These are the three principles originally generated in manufacturing fields, but they can also be adopted and applied in services fields. JIT is associated with basic control techniques. TQM is a set of basic techniques to reduce process variance. HRM is a set of practices that shape the organizational environment in which the basic techniques are implemented (Shamah, 2013; Furlan et al., 2011).

\section{Lean Healthcare Implementation and Performance}

Recent studies have explored the relationship between lean healthcare bundling practices and healthcare performance. Many studies had proven that implementation lean in healthcare lead positive results for healthcare performance. According to Shazali et al., (2013), two healthcare organizations in the US showed positive effect on productivity, cost, quality and timely delivery of services after applying lean through organization. Lean system increases the customer satisfaction, financial savings and levels of knowledge management; and a reduction in inventories and process wastes (AL-Najem et al., 2013). According to Jorma et al., (2016), the most important targets in healthcare lean implementations are cost reductions and increment of productivity simultaneously.

From 2003 to 2015, the selected measurements of performance to investigate the effects of lean bundles vary considerably between researches. Hon (2005) measured lean performance by calculating time, cost, quality, flexibility and productivity simultaneously. In 2007, Shah and Ward measured performance in terms of cost, quality, lead time, processing time and operations time. Alsmadi et al., (2012), Shazali et al., (2013) and Butler and Leong (2000) measured performance by different variables: customer satisfaction, employee satisfaction, cycle time, production cost, rate of assets (ROA), market share, overall productivity and labor productivity. Karim and Arif-Uzaman (2013) said that cost-related measures and competitor- related measures are most significant for lean performance evaluation and measurements.

The researchers selected Shazali et al., (2013) and Butler and Leong (2000) classifications of performance measurements and translated these dimensions to questions in the questionnaire to measure the hospital performance as a dependent variable in research model.

\section{Size of organization}

Previous studies refer to the classification of hospitals by type, by geographical areas, by function, by funding, by accreditation and by number of beds (Loux et al., 2005). Most of the classifications used measure the performance of hospitals and hospital size based on the number of beds. Hospital bed capacity is the number of beds which a hospital has been designed and constructed to contain. It may also refer to the number of beds set up and staffed for use.

Bhasin (2012) found that large organizations that implemented lean manufacturing achieved higher improvements in their performance compared to small and medium sized enterprises (SMEs). Hadid (2014) and Karim and Arif-Uz-zaman (2013) found that the firm size has an impact on the adaptation of lean practices because large firms are argued to have more 
financial and human resources allowing more experimentation with new technologies and innovations (e.g. lean practices) that may improve their productivity and efficiency.

Broadly, Large Enterprises (LEs) and Small and Medium sized Enterprises (SMEs) are the two main groups of organisations. Therefore, Lean sacrifices the economies of scale of mass production and aims instead to provide superior customer value through holistic process optimisation, both within the firm and up and down the supply chain (Hu et al., 2015). Lean has been increasingly recognised as a key development concept for all types of firms to improve their operations. In the literature, it is obvious that SMEs can employ a range of approaches and lean tools to facilitate lean implementation (Hu et al., 2015).

In Jordan, the only classification for hospitals is based on two main factors; the ownership of a hospital (governmental or private sector) and the purpose of the hospital itself in terms of being an educational or non-educational hospital. This current classification in Jordan does not help the research in assessing the impact of lean implementation on hospital performance according to the size of organization. Therefore, our research classifies hospitals based on size (number of beds) as considered by Loux et al.,(2005), in which hospitals were classified into three size categories: SMEs (small (fewer than 50 beds), medium (50-99 beds), and large (100 or more beds).

\section{Research Framework}

In the light of the gap identified in the previous section, the current study proposes a conceptual model which explores the link between applying lean bundles on organization performance in Jordanian private hospitals.

Our discussion and measurement of lean bundles is necessarily related to the practices that are commonly observed in the literature describing high performance since the practices are complementary to each other. Therefore, the researchers hypothesize that simultaneous application of multiple aspects of lean bundles will have a significant positive impact on performance (Shah and Ward, 2003; Carlborg et al., 2013).

We use seven items for JIT, four items for TQM, nine items for HRM, and eight items for hospital performance. Finally, the relationship between dependent and independent variables can be modified by the size of organization (as moderate variable) depending on Rahman et al., (2010), Karim and Arif-Uz-zaman (2013).This study's research model evaluates how the following groups of variables affect the hospital performance (See Figure 1).

\section{Figure 1 here}

Therefore, based on critical review of the existing literature and the developed conceptual framework, the following hypotheses of the study have been developed:

H1: The JIT bundle has a positive and direct effect on hospital performance.

H2: The TQM bundle has a positive and direct effect on hospital performance.

H3: The HRM bundle has a positive and direct effect on hospital performance.

H4: Hospital size moderates the impact of lean bundles on hospital performance.

\section{Research Methodology}

Based on the census of economic establishments for the year 2013 issued by the Department of Statistics, there are 58 private hospitals in the various governorates of the Kingdom, and 37 of them are located in the capital, Amman. This research considered the 58 
private hospitals in Jordan as the population of the research. The sample framework is the 37 private hospitals in Amman.

According to the researchers' observation, these hospitals usually receive the large number of customers based on statistical distribution of hospitals and beds by governorates and health sectors for 2013 (Department of Statistics, 2013). The private hospitals in the capital, Amman, contain 2966 beds out of 3989 distributed in hospitals in the private sector in the Kingdom.

According to the Department of Statistics' reports for 2013, the Ministry of Health has 16464 employees compared with private health sector which employs 39263 people. Therefore, the private hospitals in the Kingdom in general, and specifically in the capital Amman have a critical role in Jordanian economy, and their management is interested in using the up-to-date systems in managing both staff and operations.

In order to achieve the research objectives, the survey has been distributed to the managers (leading positions) in some departments who obtain the knowledge about the lean practices in their hospitals and have a great understanding about the level of organizational performance. The related departments are: operational department, marketing department, quality assurance department, HRM department, and supply chain department. 5 participants representing each hospital have been selected. The researcher chose the purposive sampling technique to select the research sample. According to the data, a total of 105 questionnaires were returned from 185 questionnaires distributed to 37 hospitals, 105 of which were useable. This translates into a response rate of $56.8 \%$.

The 20 items concerning lean bundles are measured on a 1-5 Likert scale ranging from strongly disagree (1) to strongly agree (5) asking informants for their perception of the actual implementation of each practice. The eight items concerning performance are measured on a 1-5 Likert scale ranging from "much worse" to "much better" in this study.

\section{Profile of firm}

\section{Table II here}

Table II indicates that $57 \%$ of the sample is classified as big hospital (more than 100 beds) and this requires more staff to make the daily work professionally. This manifests that $62 \%$ have more than 200 employees. It is also found that $44.8 \%$ of the sample have been established for more than 20 years, this is due to the fact that health sector is one of the oldest service sectors in Jordan.

\section{Validity and reliability}

Convergent and discriminate validity were both assessed using a confirmatory factor analysis (CFA) model testing approach. The fit indices are the $\chi 2 / \mathrm{df}=1.629$, standardized root mean square residual $(\mathrm{SRMR})=0.056$, comparative fit index $(\mathrm{CFI})=.906$, and the incremental fit index $($ IFI $)=90.8$. According to the threshold values suggested by $\mathrm{Hu}$ and Bentler (1999), our model can be accepted. The discriminate validity was supported because the average variance extracted (AVE) is greater than 0.50 and square root of AVE is greater than each correlation coefficient as shown in table III. Convergent validity of the measured variables were verified through confirmatory factor analysis and correlation analysis, because (1) all item loadings should be significant and exceed 0.7; (2) composite reliabilities (CR) should be more than 0.8; 
and (3) average variance extracted (AVE) for each construct should exceed 0.50 were well above the recommended value shown in table IV. Thus, convergent validity was supported. Cronbach's alpha is used to assess the reliability of scales, existing scales should have alpha values higher than .70 (Hair et al., 1995), all constructs Cronbach's alpha were ranged from .710 to .908 which confirm the scale reliability.

An important aspect of construct validity is the validation of second-order constructs as depicted in Figure 2. According to Marsh and Hocevar, (1985), second order validity exists if target coefficient $(\mathrm{T})$ is calculated as the ratio of the chi-square of the first-order model to the chi-square of the second order model between $0.80-1.00$. The results of analysis indicted the target coefficient is equal $.94(438.201 / 463.789)$ which confirm existence of a second-order construct.

\section{$\underline{\text { Table III here }}$}

Table IV here

Figure 2 here

Finally, because self-reported, single-respondent data, common method variance (CMV) might be a threat to the validity of our results. CMV arises because of respondents' need to provide consistent answers and/or answers that are socially desirable. We conducted Harman's single factor (one-factor) test for the possibility of CMV in the single-respondent data of the sample (Podsakoff et al., 2003). Confirmatory factor analysis (CFA) was performed to compare $\chi^{2}$ difference between a single-factor model where all the measurement items were loaded onto a single factor and a model where the measurement items were loaded onto the study factors. The chi-square test demonstrated that the four-factor model was superior to the single-factor model $\left(\Delta \chi^{2}=321.953 ; \Delta \mathrm{df}=8 ; P<0.01\right)$. Consequently, according to this method, no CMV problem should be expected.

\section{Analysis of lean bundles implementation JIT (Just in Time)}

Table IV intended to investigate just in time practices in surveyed hospitals. The results show high degree of implementing Just In Time bundles. The private hospitals in Jordan have a good knowledge about how to deal with suppliers and there is an effective supplier participation in operational system. Lack of sufficient experience in how to deal with the optimum setups got the lowest results because the hospitals are located within the service sector, not industrial.

\section{HRM (Human Resources Management)}

Hospitals realize that greater employee involvement has the central role in determining both the competitive advantage of the firm and the quality of services. Hospital structure is relatively flat (Horizontal structure) shows the lowest results, since the administration system used in sample organizations is centralized, due to the dominant use of vertical organizational chart. The use of such system is due to the application of traditional methods in administration that rely on administrative hierarchy.

TQM (total quality management)

The quality issues have been discussed in health care for a number of years, and quality programs are required for accreditation by HCAC. Hospital adopting direct contact methods with 
customers got the highest results, because they are aware that in Jordan's highly competitive market, if these hospitals want to survive, they should maintain an accepted level of customer satisfaction and loyalty.

\section{Hospital performance}

Every hospital in the sample has a vigorous inclination toward customer satisfaction. This result also indicates that administrators are pursuing customer satisfaction more than any other performance dimensions. So, better outcomes for patients generally imply more accessible care with shortened treatment time and waiting time (Shazali et al., 2013). Current Ratio (Current Assets/Current Liabilities) got the lowest results, because few respondents of the questionnaire have information about financial profile of their firms. Therefore, most of the answers of these questions depend on the respondents ' own estimations and expectations.

\section{Testing the research hypotheses}

Structural Equation modeling (SEM) was needed to test the proposed hypotheses and multivariate relationships. The results of SEM for the hypothesized model on Table $\mathrm{V}$ and figure 3 show that the path from lean bundles to hospital performance. The model fit indices are $\chi 2 / \mathrm{df}=$ (1.690), $\mathrm{CFI}=.902, \mathrm{RMSEA}=0.078$, and $\mathrm{SRMR}=0.0663, \mathrm{TLI}=.904$, these indices are acceptable (Hu and Bentler, 1999).

\section{Figure 3 here}

Table V here

The results of the analysis showed that there is a positive significant impact of JIT on hospital performance supporting Hypothesis $1(\beta=0.295, \mathrm{P}<0.05)$. The benefits gained from just in time implementation included lower non-value added activities, lower inventory level, higher quality, higher flexibility, and better response time and all these benefits improved organizational performance of hospitals in terms of cost reduction, productivity, inventory minimization and quality. Therefore, H1 was accepted.

HRM and TQM are found to significantly influence hospital performance. Thus, the proposed positive effect $(\mathrm{H} 2)$ and $(\mathrm{H} 3)$ are supported where $(\beta=0.314, \mathrm{P}<0.05)$ and $(\beta=-.217, \mathrm{P}$ $<0.05$ ) accordingly.

In addition, each of the dimensions of lean bundles; JIT, TQM, and HRM explained a variance of $51 \%$ in hospital performance. From previous results, the research emphasize that lean bundles should not be implemented individually and no practice can stand alone and be expected to achieve better performance than all practices combined. The findings in this section agree with the previous researches done in the field (Furlan et al., 2011; Shah and Ward 2007).

To test (H4), a multi-group analysis was used via Amos. This procedure satisfies the recommended guidelines of having at least a couple of cases per free parameter in each model for each large and SMEs (Marsh et al., 1998). This research first compared a fully constrained model in which the paths are constrained equally across subgroups to an unconstrained model. The results on table VI showed that there is no significant differences in the impact of lean bundles on hospital performance between large and small and medium hospital $(\Delta \chi=23.5$, $\mathrm{p}>0.05$ ). Thus $\mathrm{H} 4$ is not supported.

\section{Table VI here}




\section{Discussion, conclusion and implications}

The findings of this study contribute to the existing literature of knowledge by studying the effect of the implementation of lean bundles on hospital performance. The results of data analysis revealed that the implementation of lean bundles in Jordanian private hospitals has a positive effect on overall healthcare performance and has a positive impact on quality, cost, patient and staff satisfaction.

The result of our study indicates that TQM implementation helps hospitals to identify and eliminate areas generating the most waste and to improve department workflows, thereby increasing overall service quality. Therefore, the results of our study are consistent with the findings of previous research studies such as Rocha-lona et al. (2013) and Abdelhadi (2015) who found that TQM leads to improve performance by improving and sustaining the quality of service

Many previous research studies such as Taj and Morosan (2011) and Shah and Ward (2007) stressed the role of employees, as they are the key to problem-solving team, lead process/service improvement efforts and maintain excellent records of all activities regularly which leads to improve all over productivity, which is one of the most important criteria of performance. The research findings indicated that HRM, as one of the lean bundles, brings benefits to hospitals as performance improvement. Thus, our findings are in line with previous research done in the field which illustrated a strong relationship between human resource management and hospital performance. For instance, Bonavia and Marin-Garcia, (2011), found that some of the HRM practices have a significant impact on employee turnover, and productivity.

Our findings pointed out that JIT minimizes wastes generated in the process, ensuring greater productivity, reducing the required time from patients and processed materials, and forcing hospitals to deal with suppliers, service providers, and customers all over the world. Thus, the findings of the present research confirm some previous findings presented in the existing literature (Belekoukias et al., 2014; Nawanir et al., 2013; Dora et al., 2013).

We expected and hypothesised that hospital size moderates the impact of lean bundles on hospital performance. The results of data analysis were in some way surprising and our hypothesis was not supported. However, other authors have found different results.

Many researchers have assumed that size does not affect a firm's ability to implement lean system, and that SMEs can implement such systems just as effectively as large business (Shah and Ward, 2003; AL-Najem et al., 2013; Raghunath and Jayathirthav, 2014; HU et al., 2015). In reality, large companies and SMEs are able to gain the benefits of lean system (Raghunath and Jayathirthav, 2014). According to $\mathrm{Hu}$ et al., (2015), lean can be suitable to all sizes of enterprise in their activities to become more competitive to sustain, and possibly enhance, their position in the modern marketplace. Rymaszewska (2014) emphasize the successful adoption of lean among SMEs. The author highlights the capability of lean to address the challenges that companies, regardless of their size, face.

Strong leadership culture and committed management support the cornerstone for success in implementing any idea regardless of organisation size (Achanga et al., 2006).

SMEs have a better chance of adapting to change compared with large firms, as they are less hierarchical and less bureaucratic than large firms, and can therefore adopt and form the information across entire departments more efficiently than large one (HU et al., (2015). According to Belekoukias et al. (2014), the waste minimization affects more SMEs compared to large organisations. SMEs are privately owned, with the owner taking a long-term perspective 
and commitment to developing and sustaining their business. Shah and Ward (2003) found that it is not always advantageous that large size will lead to higher operational performance and that in many cases; large size has a negative impact on the operational performance when the effects of JIT, TQM, TPM and HRM are taken into consideration. Large organizations suffer from structural inertial forces that negatively affect the implementation of lean manufacturing practices.

According to Shazali et al., (2013) lean initiative does not focus on large scale investments, but it gives healthcare organizations an alternative methodology for achieving improvement without high investments. In addition, these results are inconsistent with the results of previous studies, including Bhasin (2012) and Rahman et al., (2010). The main reason for the difference in results is the study environment. Most of the previous studies that used the size of organization as a moderate variable of the relationship between lean bundles and performance done in industrial environment and manufacturers as a targeted sample. While the study environment in this research is the service environment and healthcare sector which is a targeted sample. The organizational performance of those hospitals can be driven substantially by lean system implementation without significant differences of the advantages that depend on size.

The results of this study offer several managerial 'take-away' implications for practitioners and policy makers in order to enhance the implementation of lean bundles, as an effective approach that can dramatically improve the organizational performance of hospitals. Firstly, the tools of lean bundles should be used effectively to reduce the time, effort and resources required for improvement in the health care sector. Therefore, public policy makers in Jordan should increase their awareness of lean bundles, concepts and benefits for improving service quality and optimizing hospital performance in Jordan.

Secondly, hospitals should have an effective leadership at the top and at the middle management levels to eliminate all obstacles towards the achievement of lean bundles goals. Moreover, the top management in healthcare sector must educate and empower staff which leads to the involvement of all the employees in the process.

\section{Limitations and implications for future studies}

Although the study objectives were accomplished, several limitations of the study should be noted.

Firstly, this study was limited to private hospitals of a certain health sector within a specific small country context. Therefore, caution must be exercised in extending and generalizing our findings to large public hospitals and other contexts. However, our study could be considered as a foundation for future studies in other countries and sectors. In particular, it is recommended to replicate our study in many other service industries such as hotel industry, consultancy services and telecommunications industry.

Secondly, not all the groups of variables of lean system implementation that affect the hospital performance were examined, and there might be other factors influencing the hospital performance.

Finally, it is recommended to develop more cross-sector comparisons between the service and manufacturing sectors, and assess the readiness of SMEs to embark on a lean journey 
References

Abdelhadi, A. (2015), 'Investigating Emergency Room Service Quality Using Lean Manufacturing', International Journal of Health Care Quality Assurance, Vol. 28 No. 5, pp. 510-519.

Achanga, P., Shehab, E., Roy, R., and Nelder, G. (2006), 'Critical Success Factors for Lean Implementation within SMEs', Journal of Manufacturing Technology Management, Vol. 17 No. 4, pp. 460-471.

Albliwi, A., Antony, .J, and Lim, H. (2015), 'A Systematic Review of Lean Six Sigma for the Manufacturing Industry', Business Process Management Journal, Vol. 21 No. 3.

AL-Najem, M., Dhakal, H., Labib, A., and Bennett, N. (2013), 'Lean Readiness Level within Kuwaiti Manufacturing Industries", International Journal of Lean Six Sigma, Vol. 4 No. 3 , pp. $280-320$.

Al-Saa'da, J., Taleb, A., Abdallat, A., Elian, M., Al-Mahasneh, A., Nimer, A., and Al-Weshah, A. (2013), 'Supply Chain Management and Its Effect on Health Care Service Quality: Quantitative Evidence from Jordanian Private Hospitals', Journal of Management \& Strategy, Vol. 4 No. 2, pp. 42-51.

Alsmadi, M., Almani, A., and Jerisat, R. (2012), 'A Comparative Analysis of Lean Practices and Performance in the UK Manufacturing and Service Sector Firms', Total Quality Management \& Business Excellence, Vol. 23 No. 3-4, pp. 381-396.

Behrouzi, F., and Wong, K. Y. (2011), 'Lean Performance Evaluation of Manufacturing Systems: a Dynamic and Innovative Approach', Procedia Computer Science, Vol. 3, pp. 388-395.

Belekoukias, I., Garza-Reyes, J. A., and Kumar, V. (2014), 'The Impact of Lean Methods and Tools on the Operational Performance of Manufacturing Organizations', International Journal of Production Research, Vol. 52 No. 18, pp. 5346-5366.

Bhasin, S. (2012), 'Performance of Lean in large Organisations', Journal of Manufacturing Systems, Vol. 31 No. 3, pp. 349-357.

Bonavia, T., and Marin-Garcia, J. (2011), 'Integrating Human Resource Management into Lean Production and their Impact on Organizational Performance', International Journal of Manpower, Vol. 32 No. 8, pp. 923-938.

Burgess, N., and Radnor, Z. (2013), 'Evaluating Lean in healthcare', International Journal of Health Care Quality Assurance, Vol. 26 No. 3, pp. 220-235.

Butler, W., and Leong, K. (2000), 'The Impact of Operations Competitive Priorities on Hospital Performance', Health Care Management Science, Vol. 3 No. 3, pp. 227-235.

Carlborg, P., Kindström, D., and Kowalkowski, C. (2013), 'A Lean Approach for Service Productivity Improvements: Synergy or Oxymoron', Managing Service Quality: An International Journal, Vol. 23 No. 4, pp. 291-304.

Cheng, S., Bamford, D., Papalexi, M., and Dehe, B. (2015), 'Improving Access to Health Services-Challenges in Lean Application', International Journal of Public Sector Management, Vol. 23 No. 22, pp. 121-135.

Cua, K., McKone, K., and Schroeder, G. (2001), 'Relationships' between Implementation of TQM, JIT, and TPM and Manufacturing Performance', Journal of Operations Management, Vol. 19 No.6, pp.675-694.

Dal Pont, G., Furlan, A., and Vinelli, A. (2008), 'Interrelationships among Lean Bundles and their effects on Operational Performance', Oper Manag Res, Vol. 1 No. 2, pp. 150-158. 
De Souza, B. (2009), 'Trends and Approaches in Lean Healthcare', Leadership in Health Services, Vol. 22 No. 2, pp. 121-139

Doolen, L., and Hacker, E. (2005), 'A Review of Lean Assessment in Organizations: an Exploratory Study of Lean Practices by Electronics Manufacturers', Journal of Manufacturing Systems, Vol. 24 No. 1, pp. 55-67.

Department of Statistics, Jordan (2013), 'Jordan in Figures', Amman: Department of Statistic (In Arabic).

Dora, M., Van Goubergen, D., Kumar, M., Molnar, A., and Gellynck, X. (2013), 'Application of Lean Practices in Small and Medium-Sized Food Enterprises', British Food Journal, Vol. 116 No. 1, pp. 125-141.

Drotz, E., and Poksinska, B. (2014), 'Lean in Healthcare from Employees' Perspectives', Journal of Health Organization and Management, Vol. 28 No. 2, pp. 177 - 195.

Esin, S., and Hial, O. (2014), 'The Effects of Total Quality Management Practices on Performance and the Reasons of and the Barriers to TQM Practices in Turkey', Advances in Decision Sciences, Vol. 2014, pp. 1-17.

Farzad, B., and Kuan, W. (2011), 'An Investigation and Identification of Lean Supply Chain Performance Measures in the automotive SMEs', Scientific Research and Essays, Vol. 6 No. 24, pp. 5239-5252.

Furlan, A., Vinelli, A., and Dal Pont, G. (2011), 'Complementarity and Lean Manufacturing Bundles: an Empirical Analysis', International Journal of Operations \& Production Management, Vol. 31 No. 8, pp. 835-850.

Ghosh, M., and Sobek D. (2015), 'A Problem-Solving Routine for Improving Hospital Operations' Journal of Health Organization and Management, Vol. 29 No. 2, pp. 252-270.

Hadid, W. (2014), 'The Relationship between Lean Service, Activity-Based Costing and business strategy and their Impact on Performance', Brunel University Brunel Business School, $\mathrm{PhD}$ Theses.

Hadid, W and Mansouri, A. (2014), 'The Lean-Performance Relationship in Services: a Theoretical Model'. International Journal of Operations \& Production Management, Vol. 34 No. 6, pp. 750-785.

Hair, F., Anderson, E., Tatham, L., and Black, C. (1995), Multivariate Data Analysis, 4th ed. Prentice Hall, Upper Saddle River, NJ.

Halasa, Y., and Nandakumar, K. (2009), 'Factors Determining Choice of Health Care Provider in Jordan', Eastern Mediterranean Health Journal, Vol. 15 No. 4, pp.959-968.

Hon, B. (2005), 'Performance and Evaluation of Manufacturing Systems', CIRP AnnalsManufacturing Technology, Vol. 54 No. 2, pp. 139-154.

Hu, L., and Bentler, M. (1999), 'Cutoff Criteria for Fit Indexes in Covariance Structure Analysis: Conventional Criteria Versus New Alternatives', Structural Equation Modelling, Vol. 6 No. 1, pp. 1-55.

$\mathrm{Hu}$, Q., Mason, R., Williams, S., and Found, P. (2015), 'Lean Implementation within SMEs: a Literature Review', Journal of Manufacturing Technology Management, Vol. 26 No. 7.

Jadhav, J., Mantha, S., and Rane, S. (2014), 'Exploring Barriers in Lean Implementation', International Journal of Lean Six Sigma, Vol. 5 No. 2, pp. 122-148.

Jagdish, J., Mantha, S., and Santosh, R. (2014), 'Development of Framework for Sustainable Lean Implementation: an ISM Approach', Journal of Industrial Engineering International, Vol. 10 No. 27 , pp. 4-27. 
Jarrett, P. (2006), 'An Analysis of International Health Care Logistics: The Benefits and Implications of Implementing Just-in-Time Systems in the Health Care Industry', Leadership in Health Services, Vol. 19 No. 1, pp. 1-10.

Jorma, T., Tiirinki, H., Bloigu, R., and Turkki, L. (2016), 'Lean Thinking in Finnish Healthcare', Leadership in Health Services, Vol. 29 No. 1, pp. 9 - 36.

Karim, A., and Arif-Uz-zaman, K. (2013), 'A Methodology for Effective Implementation of Lean Strategies and its Performance Evaluation in Manufacturing Organizations', Business Process Management Journal, Vol. 19 No. 1, pp. 169-196.

Kannan, V., and Tan, K. (2005), 'Just in Time, Total Quality Management, and Supply Chain Management: Understanding their Linkages and impact on Business Performance', Omega, Vol. 33, pp. 153-162.

Loux, L., Payne, S., and Knott, A. (2005), Comparing Patient Safety in Rural Hospitals by Bed Count, Agency for Healthcare Research and Quality, Rockville Md.

Lorden, A., Zhang, Y., Lin, S., and Cote, M. (2014), 'Measures of Success: The Role of Human Factors in Lean Implementation in Healthcare', Quality Management Journal, Vol. 21 No. 3, pp. 26-37.

Laura, R., and Priti, Sh. (2011), 'Lean Service Implementation in Hospital: A Case Study Conducted in University Clinical Centre of Kosovo, Rheumatology Department', Master Thesis, Umea School of Business, Sweden.

Leggat, S., Bartram, T., Stanton, P., Bamber, G., and Sohal A. (2015), 'Have Process Redesign Methods, such as Lean, been Successful in Changing Care Delivery in Hospitals? A Systematic Review', Public Money \& Management, Vol. 35 No.2, pp. 161-168.

Marodin, A., and Saurin, A. (2013), 'Implementing Lean Production Systems: Research Areas and Opportunities for Future Studies', International Journal of Production Research, Vol. 51 No. 22, pp. 6663-6680.

Marsh, W., Hau, T., Balla, R., and Grayson, D. (1998), 'Is more ever too much? The Number of Indicators per Factor in Confirmatory Factor Analysis', Multivariate Behavioural Research, Vol. 33 No. 2, pp. 181-220.

Marsh, H., and Hocevar, D. (1985), 'Application of Confirmatory Factor Analysis to the Study of Self-concept: First- and Higher-order Factor Models and their Invariance Across Groups', Psychological Bulletin, Vol. 97 No. 3, pp. 145-52.

Mannon, M. (2014), 'Lean Healthcare and Quality Management: The Experience of ThedaCare', Quality Management Journal, Vol. 21 No. 1, pp. 7-10.

Martínez-Jurado, P., Moyano-Fuentes, J., and Gómez, P. (2013), 'HR Management during Lean Production Adoption', Management Decision, Vol. 51 No. 4, pp. 742 - 760.

Med Tourism Co, LLC http://www.medicaltourismco.com/jordan-hospitals/medical-tourismjordan.php (last accessed April 2014).

Nawanir, G., Teong, Lim., and Othman S. (2013), 'Impact of Lean Practices on Operations Performance and Business Performance', Journal of Manufacturing Technology Management, Vol. 24 No. 7, pp. 1019-1050.

Nayar, P., Ojha, D., Fetrick, A., and Nguyen, A. (2016), 'Applying Lean Six Sigma to improve Medication Management', International Journal of Health Care Quality Assurance, Vol. 29 No. 1, pp. 16 - 23.

Nicholas, J. (2012), 'An Integrated Lean-Methods Approach to Hospital Facilities Redesign', Hospital Topics, Vol. 90 No.2, pp. 47-55. 
Podsakoff, P., MacKenzie, S., Lee, J., and Podsakoff, P. (2003), 'Common Method Biases in Behavioural Research: a Critical Review of the Literature and Recommended Remedies', Journal of Applied Psychology, Vol. 88 No. 5, pp. 879-903.

Poksinska, B., Swartling, D., and Drotz, Total. (2013), 'The Daily Work of Lean Leaders Lessons from Manufacturing and Healthcare', Erik Quality Management, Vol. 24 No. 8, pp. 886-898.

Rahman, S., Laosirihongthong, T., and Sohal, S. (2010), 'Impact of Lean Strategy on Operational Performance: a Study of Thai Manufacturing Companies', Journal of Manufacturing Technology Management, Vol. 21 No. 7, pp. 839-852.

Raghunath, A., and Jayathirtha, R.V. (2014), 'Six Sigma Implementation by Indian Manufacturing SMEs - an Empirical Study', Academy of Strategic Management Journal, Vol. 13 No. 1, pp. 35-55.

Rocha-Lona, L., Garza-Reyes, A., and Kumar, V. (2013), Building Quality Management Systems: Selecting the Right Methods and Tools, CRC Press.

Rymaszewska, Anna. (2014), 'The Challenges of Lean Manufacturing Implementation in SMEs', Benchmarking: An International Journal, Vol. 21 No. 6, pp. 987-1002.

Sara, T., Monica E., Carol T., Mats B., and Johan H. (2015), 'Agile, a Guiding Principle for Health Care Improvement?', International Journal of Health Care Quality Assurance, Vol. 28 No. 5, pp. 486-493.

Shah, R. and Ward, P.T. (2003), 'Lean Manufacturing: Context, Practice Bundles, and Performance', Journal of Operations Management, Vol. 21 No. 2, pp. 129-149.

Shah, R., and Ward, T. (2007), 'Defining and Developing Measures of Lean Production', Journal of Operations Management, Vol. 25 No. 4, pp. 785-805.

Shamah, A. (2013), 'Measuring and Building Lean Thinking for Value Creation in Supply Chains', International Journal of Lean Six Sigma, Vol. 4 No. 1, pp. 17-35.

Shazali, A., Habidin, F., Ali, N., Khaidir, A., and Jamaludin, H. (2013), 'Lean Healthcare Practice and Healthcare Performance in Malaysian Healthcare Industry', International Journal of Scientific and Research Publications, Vol. 3 No. 1, pp. 1-5.

Silva, I., Seraphim, E., Agostinho, O., Junior, O., and Batalha, G. (2015), 'Lean Office in Health Organization in the Brazilian Army', International Journal of Lean Six Sigma, Vol. 6 No. 1, pp. 2 - 16.

Taj, S., and Morosan, C. (2011), 'The impact of Lean Operations on the Chinese Manufacturing Performance', Journal of manufacturing technology management, Vol. 22, No. 2, pp. 223240.

Tan, W. (2011), 'Managing Lean Projects: Understanding the Structures of Lean Production', International Journal of Construction Management, Vol. 11 No. 3, pp. 67-78.

Wong, W., Ignatius, J., and Soh, K. (2014), 'What is the Leanness Level of your Organization in Lean Transformation Implementation? An Integrated Lean Index Using ANP Approach', Production Planning \& Control: The Management of Operations, Vol. 25 No. 4, pp. 273-287.

Wickramasinghe, D., and Wickramasinghe, V. (2011), 'Perceived Organisational Support, Job Involvement and Turnover Intention in Lean Production in Sri Lanka', International Journal of Advanced Manufacturing Technology, Vol. 55 No. 5-8, pp. 817-830.

Zhou, B. (2012), 'Lean Principles, Practices, and Impacts: a Study on small and Medium-Sized Enterprises (SMEs)’, Annals of Operations Research, No. 1, pp. 1-18. 
Table I: Reviewing the body of knowledge for lean bundling practices

\begin{tabular}{|c|c|c|c|c|c|c|c|c|c|c|c|}
\hline Research & $V S$ & $C I$ & $J I T$ & $T Q M$ & Perfection & $H R M$ & $\begin{array}{l}\text { Zero } \\
\text { defects }\end{array}$ & $M F T$ & VIS & $T P M$ & COST \\
\hline Albliwi et al., 2015 & & & $\bullet$ & $\bullet$ & & $\bullet$ & & & & & $\bullet$ \\
\hline Hu et al., 2015 & & & $\bullet$ & $\bullet$ & & $\bullet$ & & & & & $\bullet$ \\
\hline Jagdish et al., 2014 & 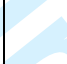 & & $\bullet$ & $\bullet$ & & $\bullet$ & & & & & \\
\hline Belekoukias et al. ,2014 & 8 & $\bullet$ & $\bullet$ & & & $\bullet$ & & & & $\bullet$ & \\
\hline Tan, 2011 & $\bullet$ & 0 & $\bullet$ & & & $\bullet$ & & & & & \\
\hline Shazali et al., 2013 & & $\bullet$ & & & & $\bullet$ & & & & & \\
\hline $\begin{array}{l}\text { Burgess and Radour, } \\
2013\end{array}$ & $\bullet$ & $\bullet$ & $\bullet$ & 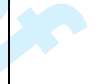 & - & & & & & & \\
\hline Alsmadi et al. ,2012 & & $\bullet$ & $\bullet$ & - & 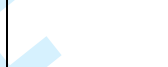 & $\bullet$ & & & & & \\
\hline Zhou, 2012 & & & $\bullet$ & $\bullet$ & ( & & & & & & \\
\hline Dal Pont et al., 2008 & & & $\bullet$ & $\bullet$ & & - & & & & & \\
\hline Behrozi \& Wong, 2011 & & • & • & & & 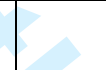 & - & $\bullet$ & $\bullet$ & & \\
\hline Furlan et al., 2011 & & $\bullet$ & $\bullet$ & $\bullet$ & & $\bullet$ & & & & & \\
\hline Farzad and Kuan, 2011 & & $\bullet$ & $\bullet$ & $\bullet$ & & $\bullet$ & & & & & $\bullet$ \\
\hline Laura and Priti, 2011 & $\bullet$ & & $\bullet$ & & $\bullet$ & $\bullet$ & 8 & & & & \\
\hline Cua et al., 2001 & & & $\bullet$ & $\bullet$ & $\bullet$ & & & & & $\bullet$ & \\
\hline Shah and Ward, 2003 & & & $\bullet$ & $\bullet$ & & $\bullet$ & & & & $\bullet$ & \\
\hline
\end{tabular}


Table II: Descriptive statistics of sample's organisation characteristics

\begin{tabular}{|l|l|l|l|l|l|l|l|l|}
\hline Number of employees & Freq & $\%$ & $\begin{array}{l}\text { Age of } \\
\text { hospital }\end{array}$ & Freq & $\%$ & Number of beds & Freq & $\%$ \\
\hline 50 employees or less & 1 & $1 \%$ & $0-3$ & 11 & $10.5 \%$ & Less than 50 & 20 & $19.1 \%$ \\
\hline Between 51and 100 & 13 & $12.4 \%$ & $4-7$ & 0 & $0 \%$ & From 50 to 100 & 25 & $23.8 \%$ \\
\hline Between 101 and 150 & 14 & $13.3 \%$ & $8-11$ & 8 & $7.6 \%$ & More than 100 & 60 & $57.1 \%$ \\
\hline Between 151and 200 & 12 & $11.4 \%$ & $12-15$ & 24 & $22.9 \%$ & Total & 105 & $100 \%$ \\
\hline More than 200 & 65 & $61.9 \%$ & $16-19$ & 15 & $14.3 \%$ & & & \\
\hline Total & 105 & $100 \%$ & +20 & 47 & $44.8 \%$ & & & \\
\hline
\end{tabular}

Table III: Interconstruct Correlations

\begin{tabular}{|l|c|l|l|l|}
\hline constructs & JIT & TQM & HRM & Performance \\
\hline JIT & $(.735)$ & & & \\
\hline TQM & $.395^{* *}$ & $(.774)$ & & \\
\hline HRM & $.630^{* *}$ & $.516^{* *}$ & $(.728)$ & $(.831)$ \\
\hline performance & $.618^{* *}$ & $.642^{* *}$ & $.640^{* *}$ & - \\
\hline $\begin{array}{l}\text { Note: Square root of AVE are shown on the diagonal of each matrix; } \\
\text { Interconstruct correlation is shown off the diagonal }\end{array}$ \\
\hline$* *$ Sig<.01, *Sig<.05
\end{tabular}

Table IV: Measurement of confirmatory factor analysis - convergent validity/ Means and Standard Deviations for sample's responses toward research questions.

\begin{tabular}{|c|c|c|c|c|c|c|c|c|}
\hline$J I T$ & $\begin{array}{l}\text { Factor } \\
\text { loading }\end{array}$ & Mean & stdev & Level & Rank & $C R$ & $A V E$ & $\alpha$ \\
\hline $\begin{array}{l}\text { Hospital usually completes daily schedule as } \\
\text { planned }\end{array}$ & 0.764 & 3.87 & .858 & high & 3 & \multirow{7}{*}{.86} & \multirow{7}{*}{.54} & \multirow{7}{*}{.862} \\
\hline $\begin{array}{l}\text { The layout of institution floor facilitates low } \\
\text { inventories and fast throughput }\end{array}$ & 0.707 & 3.78 & .740 & high & 5 & & & \\
\hline $\begin{array}{l}\text { Suppliers frequently deliver materials to } \\
\text { hospital }\end{array}$ & 0.784 & 4.15 & .703 & high & 1 & & & \\
\hline Customers receive JIT deliveries from hospital & 0.711 & 3.84 & .846 & high & 4 & & & \\
\hline Hospital have low setup times of equipment's & 0.722 & 3.59 & .858 & Medium & 7 & & & \\
\hline Hospital actively develops customer's services & 0.733 & 4.12 & .850 & high & 2 & & & \\
\hline $\begin{array}{l}\text { Hospital uses pull-based production system } \\
\text { (according to customer order) }\end{array}$ & 0.733 & 3.72 & .909 & high & 6 & & & \\
\hline \multicolumn{2}{|l|}{ Overall mean } & 3.86 & & high & & \\
\hline
\end{tabular}




\section{HRM (human resource management)}

Hospital encourages team work to achieve common goals, rather than encourages individual work

Management tells us why our suggestions either implemented or not

Hospital structure is relatively flat (Horizontal structure)

Employees receive training to perform multiple

tasks

Employees receive training and development in workplace skills regularly

Hospital adopts all aspects of continuous improvement

Employees undergo cross-functional training/

Employees tend to involve problem solving teams

Employees lead service/process improvement efforts

Employees are empowered and encouraged to improve the services/ processes within the hospital

Overall mean

TQM (total quality management)

Hospital adopts direct contact methods with customers

Customers provide feedback on quality and delivery performance

Hospital employs regular customer satisfaction surveys

Hospital frequently in close contact with suppliers

Overall mean

\section{Hospital performance}

\section{Overall customer satisfactions}

Worker Productivity.

Revenue Growth.

Current Ratio (Current Assets/Current Liabilities)

Excess of income over expenses.

Quick delivery compare to competitors

Cost of services relative to competitors

common market share (hospital revenues/related

market revenues)

Overall mean

\begin{tabular}{|c|c|c|c|c|c|c|c|}
\hline 0.729 & 4.17 & .837 & high & 1 & & & \\
\hline 0.648 & 3.79 & .825 & high & 3 & & & \\
\hline 0.694 & 3.51 & .894 & Medium & 9 & & & \\
\hline 0.688 & 3.78 & .847 & high & 4 & & & \\
\hline 0.749 & 3.71 & .883 & high & 8 & .91 & .53 & .908 \\
\hline
\end{tabular}

0.8

0.831

\begin{tabular}{l|l|l|l}
3.86 & .815 & high & 2
\end{tabular}

0.807

\begin{tabular}{l|l|l} 
& 3.73 & .8
\end{tabular}

\begin{tabular}{l|l}
\hline & 0.724
\end{tabular}

0.724

0.673

\begin{tabular}{|l|l|l|l}
\hline 3.73 & .828 & high & 7 \\
\hline 3.77 & .827 & high & 5 \\
\hline 3.75 & .840 & high & 6 \\
\hline 3.79 & & high &
\end{tabular}

$\mid$


Table V: Path analysis for the constructs of the study

\begin{tabular}{|l|l|l|c|c|c|}
\hline \multicolumn{2}{|l|}{ Path } & Estimate & C.R. & $P$ \\
\hline Performance & $<---$ & JIT & .295 & 3.674 & .000 \\
\hline Performance & $<---$ & TQM & .217 & 2.977 & .003 \\
\hline Performance & $<---$ & HRM & .314 & 3.663 & .000 \\
\hline R2 & \multicolumn{3}{|l|}{.513} \\
\hline
\end{tabular}

Table VI: Results of the multigroup analysis

\begin{tabular}{|c|c|c|c|c|c|c|c|c|c|}
\hline \multicolumn{3}{|l|}{ Models } & $\chi^{2}$ & $d f$ & $\Delta \chi^{2}$ & $\Delta d f$ & $\chi^{2}$ difference test & $\begin{array}{l}\text { Small \& } \\
\text { medium } \\
\text { size }\end{array}$ & large size \\
\hline \multicolumn{3}{|c|}{ 1. Baseline Model } & 1023.2 & 504 & & & & & \\
\hline \multicolumn{3}{|c|}{ 2. Constrained Model } & 1046.7 & 531 & 23.5 & 26 & Insignificant $\mathrm{p}<0.05$ & & \\
\hline \multicolumn{3}{|c|}{ Constrained Path } & & O & & & & & \\
\hline Performance & $<---$ & JIT & 1023.2 & 505 & 0 & 1 & Insignificant $\mathrm{p}<0.05$ & .483 & .306 \\
\hline Performance & $<---$ & HRM & 1023.4 & 505 & .2 & 1 & Insignificant $\mathrm{p}<0.05$ & -.167 & .288 \\
\hline
\end{tabular}

Figure 1: Research Model

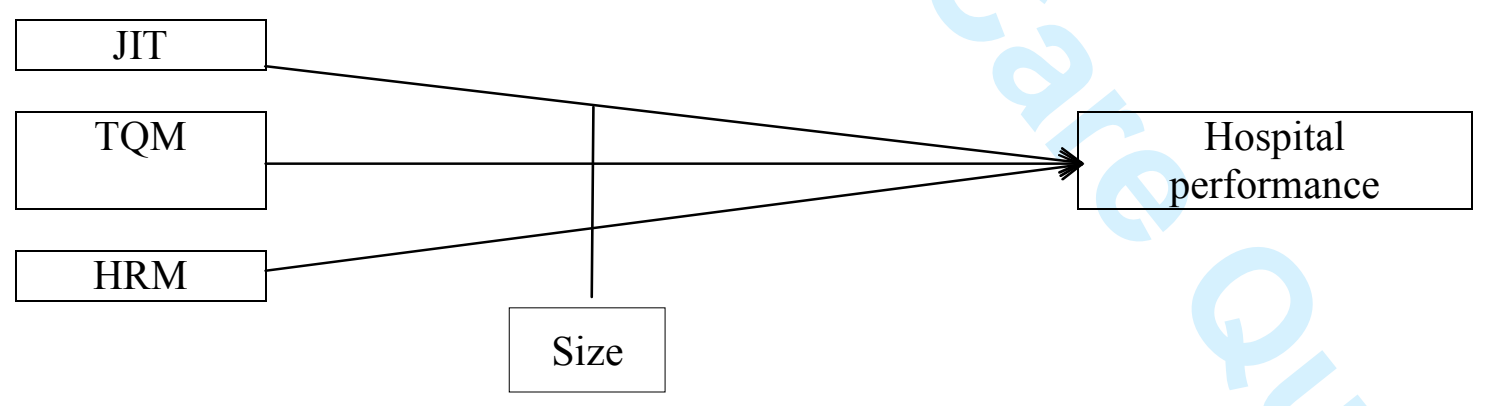


Figure 2: second-order CFA results

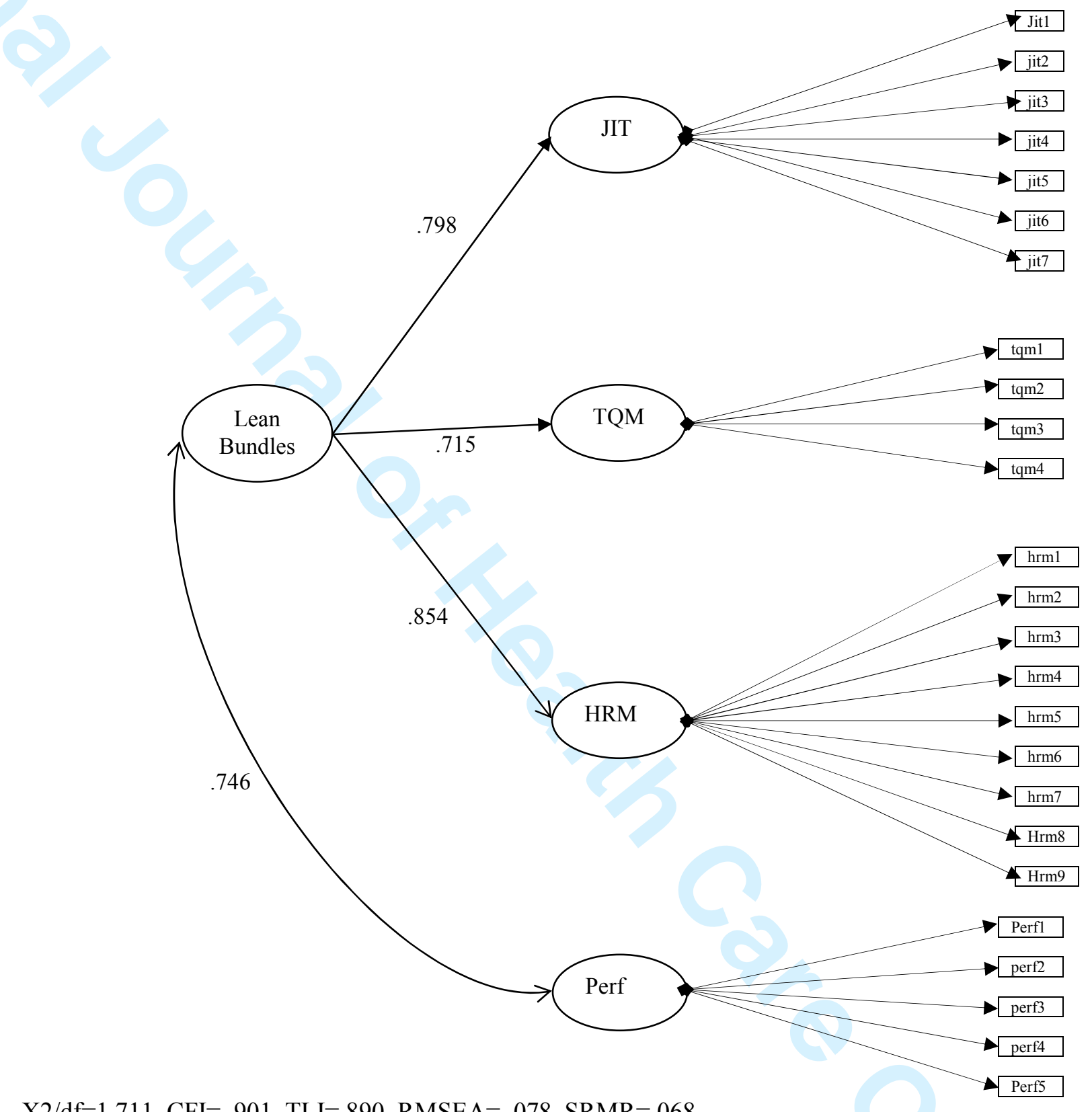

$\mathrm{X} 2 / \mathrm{df}=1.711, \mathrm{CFI}=.901, \mathrm{TLI}=.890, \mathrm{RMSEA}=.078, \mathrm{SRMR}=.068$ 
Figure 3: Structural model with parameter estimates

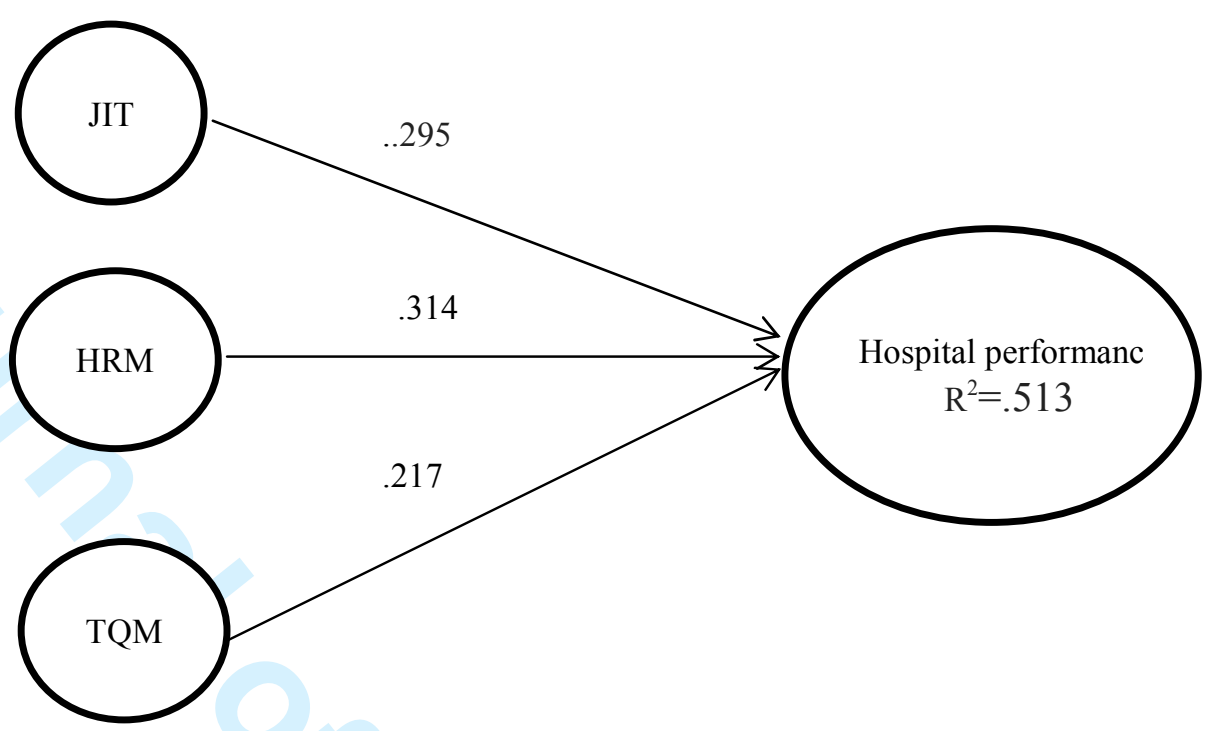

